\title{
Palaeointensity determinations and magnetic properties on Eocene rocks from Izu-Bonin-Mariana forearc (IODP Exp. 352)
}

\author{
C. Carvallo, ${ }^{1}$ P. Camps,${ }^{2}$ W. W. Sager ${ }^{3}$ and T. Poidras ${ }^{2}$ \\ ${ }^{1}$ Institut de Minéralogie, de Physique des Matériaux et de Cosmochimie, UPMC Univ Paris 06, UMR CNRS 7590, MNHN, IRD UMR 206, 4 Place Jussieu, \\ F-75005 Paris, France.E-mail: carvallo@impmc.upmc.fr \\ ${ }^{2}$ Géosciences Montpellier, CNRS and Université de Montpellier, Place Eugène Bataillon, F-34095 Montpellier, France \\ ${ }^{3}$ Earth \& Atmospheric Sciences, University of Houston, 127B Science and Research Building 1, Houston, TX 77204, USA
}

Accepted 2017 May 11. Received 2017 May 10; in original form 2017 January 27

\begin{abstract}
SUMMAR Y
IODP Expedition 352 cored igneous rocks from the Izu-Bonin-Mariana forearc crust. Cores from Sites U1440 and U1441 recovered Eocene basalts and related rocks and cores from Sites U1439 and U1442 recovered Eocene boninites and related rocks. We selected samples from Holes U1439C, U1440B and U1442A for palaeointensity measurements. Hysteresis measurements and high and low-temperature magnetization curves show that samples from Hole U1440B undergo magneto-chemical changes when heated and are mostly composed of single-domain (SD) or pseudo-single-domain (PSD) titanomaghemite. In contrast, the same measurements show that most selected samples from Holes U1439C and U1442A are thermally stable and are composed of either SD or PSD titanomagnetite with very little titanium content, or SD ferromagnetic grains with a large paramagnetic contribution. Thellier-Thellier palaeointensity experiments carried out on U1439C and U1442A samples give a good success rate of 25/60 and Virtual Dipole Moment (VDM) values between 1.3 and $3.5 \times 10^{22} \mathrm{Am}^{2}$. Multispecimen palaeointensity experiments with the domain-state corrected method carried out on 55 samples from Hole U1440B (divided into four groups) and 20 from Hole U1439C gave poor quality results, but indicated a VDM around 4-6 $\times 10^{22} \mathrm{Am}^{2}$ in Hole U1440B forearc basalts. These results are in agreement with the few, low VDM values previously measured on Eocene rocks. However, they do not support an inverse relationship between field intensity and reversal rate for this period of time, since the Eocene reversal rate was low.
\end{abstract}

Key words: Ocean drilling; Palaeointensity; Rock and mineral magnetism.

\section{INTRODUCTION}

A good knowledge of the long-term variations of geomagnetic palaeofield intensity is essential for a complete description of field history. Absolute palaeointensity data are difficult to recover because of the high failure rate of the standard, widely used ThellierThellier method (Thellier \& Thellier 1959). This method is the most reliable palaeointensity method because it reproduces the process of thermoremanent magnetization (TRM) acquisition by heating a sample in a laboratory field. Partly owing to the difficulty of obtaining reliable results, the palaeointensity (PINT) database (Biggin \& Paterson 2014), available at http://earth.liv.ac.uk/pint/, is unevenly distributed throughout geological time: seventy per cent of palaeointensity data are concentrated in the last $20 \mathrm{Myr}$, while 35 per cent of the data span the last $1 \mathrm{Myr}$. We therefore lack a complete description of the geomagnetic field over many timescales, particularly beyond the last million years. Thus, older measurements are of great value.

International Ocean Discovery Program (IODP) Exp. 352 during 2014 cored the Izu-Bonin-Mariana (IBM) forearc at $28^{\circ} \mathrm{N}$ with the aim of understanding oceanic crustal accretion immediately following subduction initiation. The IBM system is a predominantly submarine convergent plate boundary and is the result of $\sim 52 \mathrm{Myr}$ of subduction (Ishizuka et al. 2011; Reagan et al. 2013) of the Pacific plate beneath the eastern margin of the Philippine Sea plate. Stretching for $\sim 2800 \mathrm{~km}$ from the Izu Peninsula of Japan to Guam, the IBM system (summarized in Stern et al. 2003) has been extensively surveyed and has become an important natural laboratory for IOPP expeditions aimed at understanding subduction initiation, arc evolution and continental crust formation.

Diving and dredging on the forearc slope east of the Bonin Ridge and south of Guam recovered basaltic rocks from stratigraphic levels below the boninite layer that caps the crust. These basalts are characterized by high magnesium and low titanium content, but have chemical compositions otherwise similar to normal mid-ocean ridge basalt. However, they are not identical, and hence the term 'forearc basalt' (FAB) was coined by Reagan et al. (2010) to highlight their distinctive setting. Most of the reliable ${ }^{40} \mathrm{Ar} /{ }^{39} \mathrm{Ar}$ ages and $\mathrm{U}-\mathrm{Pb}$ zircon ages of IBM FAB are identical within error and indicate that these rocks were emplace by magmatism at $\sim 50-52 \mathrm{Ma}$, preceding 


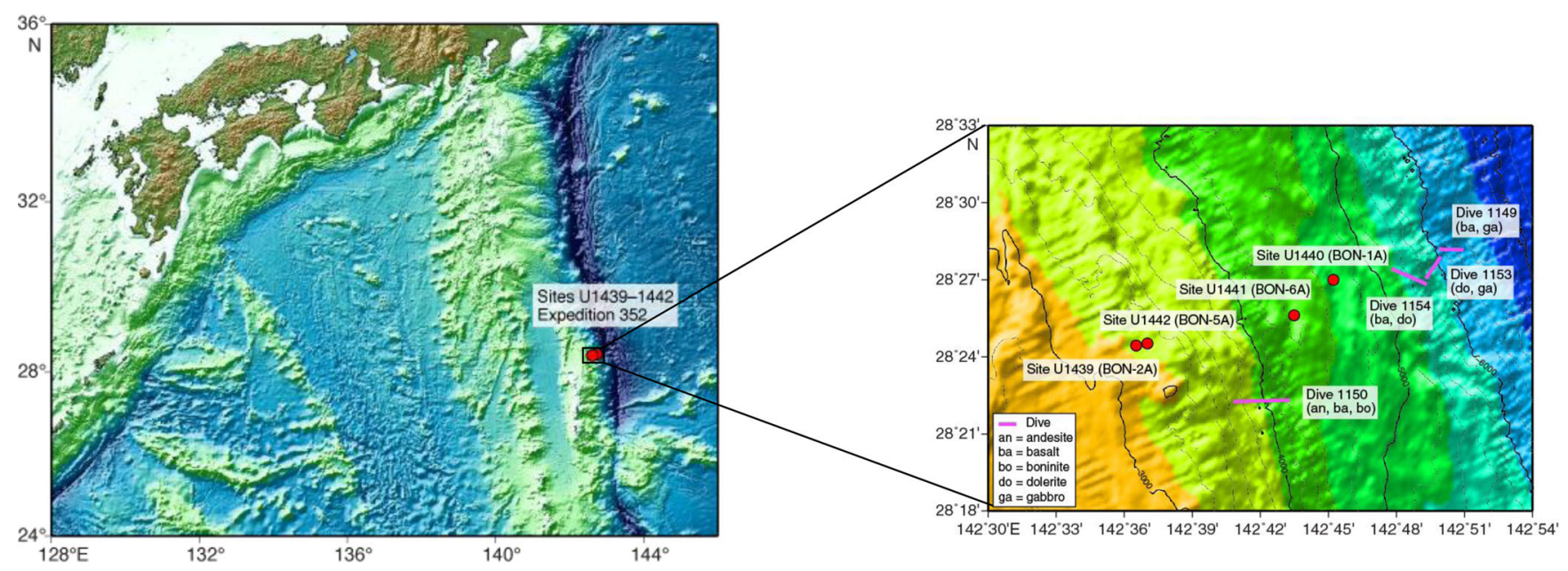

Figure 1. Map of the sites drilled during Exp. 352, and Shinkai 6500 dive sites in the Bonin forearc (from Ishizuka et al. 2011).

boninite eruption by 2-4 million years (Ishizuka et al. 2011; Reagan et al. 2013). FAB and related gabbros are thought to relate to the first magmas produced as the IBM subduction zone began to form (Reagan et al. 2010, 2017). Lavas with compositions that transition upward between FAB and boninite were recovered at Deep Sea Drilling Project (DSDP) Sites 458 and 459 in the Mariana forearc and illustrate that FAB and boninite are genetically linked (Reagan et al. 2010).

Expedition 352 successfully cored $1.22 \mathrm{~km}$ of igneous basement and $0.46 \mathrm{~km}$ of overlying sediment, providing diverse, stratigraphically controlled suites of FAB and boninites related to seafloor spreading and earliest arc development (Fig. 1; Reagan et al. 2015a). FAB and andesitic lavas with major and trace element compositions consistent with genesis by differentiation of FAB were recovered at the two deeper water sites (U1440 and U1441). Boninites and differentiated high-Mg andesites considered to be boninite-series lavas were recovered at the two shallower sites (U1439 and U1442) drilled upslope to the west. Holes U1439C and U1442A yielded entirely boninite differentiation series lavas that generally become more primitive and have lower $\mathrm{TiO}_{2}$ concentrations upward. The basalts erupted immediately after subduction initiation and have compositions similar to those generated by rapid seafloor spreading at mid-ocean ridges, with geochemistry indicating little-to-no slab input. Subsequent melting to generate boninites involved more depleted mantle, and hotter and deeper subducted components, as subduction progressed and volcanism migrated away from the trench (Reagan et al. 2017).

The recovery of such volcanic rocks provides an opportunity to perform palaeointensity measurements on whole rocks from a period for which such measurements are few. In the time range span by these rocks, only two studies of palaeointensity determinations are available. One is from submarine basaltic glass (SBG; Tauxe 2006) from DSDP Site 322 measured with the IZZI protocol that combines the Aitken (in-field, zero-field heatings) and the Coe (zero-field, infield heatings) methods (Yu \& Tauxe 2005); the other one is from plutonic rocks from Western Antarctica (Shcherbakova et al. 2012) measured with the Thellier-Coe (Coe 1967) method. The Virtual Dipole Moment (VDM) values given by these studies are between 2 and $5 \times 10^{22} \mathrm{Am}^{2}$, which is much lower than the present-day value of $\sim 8 \times 10^{22} \mathrm{Am}^{2}$. The data from the PINT database during for all of the Eocene and Palaeocene display a large variation, but the average VDM value is lower than the present day VDM value. The majority of data in Eocene-Palaeocene are derived from SBG and single-crystals (Tarduno \& Cottrell 2005), and only very few from whole rocks.

\section{SAMPLING AND SHIPBOARD MEASUREMENTS}

Routine palaeomagnetic measurements (thermal and alternatingfield demagnetizations) were carried out on the Expedition 352 samples by the shipboard scientists. Igneous rock samples from Hole U1439C have mostly low inclinations with absolute values less than $\sim 30^{\circ}$ and an average of $\sim 5^{\circ}$ (Reagan et al. 2015b). This is consistent with the hypothesis that the Izu-Bonin arc formed near the palaeoequator (Hall et al. 1995). Palaeomagnetic samples from the igneous basement section from Hole U1440B reveal a probable magnetic reversal sequence. The upper $\sim 50$ and lower $\sim 120 \mathrm{~m}$ of the section have normal polarity, whereas the intervening $\sim 70 \mathrm{~m}$ has reversed polarity (Reagan et al. 2015c). Palaeomagnetic samples from the igneous units recovered at Hole U1442A give palaeoinclinations mostly near zero (Reagan et al. 2015d). Low negative inclinations predominate in the upper part above 400 meters below sea floor (mbsf), whereas low positive inclinations are seen below $440 \mathrm{mbsf}$. These shallow inclinations are consistent with the low palaeolatitude of the Izu-Bonin arc at the time of its formation. Transitions between positive and negative inclinations above $400 \mathrm{mbsf}$ are most likely the result of secular variation at low latitudes. The shift to positive inclinations in the lower part of the hole may indicate a magnetic reversal or simply eruption in a short time interval, during which there was little secular variation.

Cylindrical specimens $2.5 \mathrm{~cm}$ in diameter were cut and trimmed to minicores $2.2 \mathrm{~cm}$ in length, whenever there was enough material in the core. Recovery in the Expedition 352 cores was generally low, so sample volume was often limited. In this situation, we cut $1.25 \mathrm{~cm}$ in diameter minicores. The remaining material (usually a 1 or $2 \mathrm{~mm}$ slice) was kept for rock magnetic experiments [hysteresis, First-Order Reversal Curve (FORC) diagrams, low-temperature and thermomagnetic measurements]. When taken from an oriented piece, the minicores were oriented relative to the vertical axis of the core. Owing to the rotary action of the coring, these samples cannot be oriented in azimuth.

We selected 93 samples for palaeointensity measurements from Holes U1439C, U1440B and U1442A. Because of the limited means of magnetic characterization on-board, we chose to sample sections 
of the core based on AF demagnetization spectra and variations of bulk susceptibility with thermal treatments. We looked for thermal demagnetizations with a stable magnetic direction, especially with a univectorial decay, and AF demagnetization spectra with an initial plateau (i.e. little initial demagnetization) which is a characteristic of single-domain (SD) grains (Dunlop \& West 1969). We also favoured samples with little susceptibility variation during thermal demagnetization, which implies that the magnetic minerals are stable during heating. This is important for the Thellier-Thellier measurements which require many heating steps. The magnetic behaviours referred to in the next part are based on these measurements, in particular shape of the thermal or AF demagnetization spectra, unblocking temperatures and order of magnitude of natural remanent magnetization(NRM).

(1) Hole U1439C. Four different igneous units were sampled (Fig. 2a): we took 5 samples from Unit 5, 17 samples from Unit 6 divided in three groups with different magnetic behaviour based on shipboard magnetic measurements, 17 samples from Unit 8 also divided in three groups with various magnetic behaviours, and 6 samples from Unit 9a. Units 5, 6 and 8 were described as pillow lavas composed of boninite or low-silica boninite, while Unit 9a is a massive single pillow-lava composed of high-magnesium andesite (evolved boninites) (Reagan et al. 2015b).

(2) Hole U1440B. Two different units were sampled (Fig. 2b): we took 8 samples in the top of Unit 2 and 20 samples in Unit 15 taken in 3 groups with different magnetic behaviours according to the shipboard measurements. Unit 2 is a massive sheet basalt unit and Unit 15 is a dike or sill complex composed of doleritic basalt at the bottom of the hole (Reagan et al. 2015c).

(3) Hole 1442A. Samples were taken from four units (Fig. 2c): five samples from Unit $1 \mathrm{~d}$, five from Unit $2 \mathrm{a}$, five from Unit $2 \mathrm{~b}$ and 5 from Unit 3. Unit 1d is characterized by high-silica boninite with a magnetic susceptibility higher than in the other boninite units. Unit 2 a consists of clasts of high-silica boninite glass and lava with chilled rims, commonly intermingled with evolved low-silica boninite (high-magnesium andesite) lava and a wide range in compositions and magnetic susceptibilities. Unit $2 \mathrm{~b}$ is composed of evolved low-silica boninite (high-Mg andesite). Section 3 is composed of boninite hyaloclastite and low-silica boninites (high-magnesium andesite; Reagan et al. 2015d).

\section{METHODS}

\subsection{Hysteresis and FORC diagrams}

FORC diagrams allow a qualitative characterization of the magnetic domain structure and magnetostatic interactions even for materials containing a mixed grain-size assemblage (Pike et al. 1999; Roberts et al. 2000; Carvallo et al. 2006). Hysteresis parameters and FORC diagrams were measured with a magnetometer ( $\mu$-VSM) from Princeton Measurements Corporation at the IPGP-IMPMC Mineral Magnetism Analytical Facility. FORC diagrams were each calculated from 200 individual FORCs measured with an averaging time of 0.1 or $0.2 \mathrm{~s}$, depending on the amount of noise. They were analysed with the VARIFORC software (Egli 2013), with a variable smoothing factor. The variable smoothing considerably reduces the noise levels by applying larger smoothing factors to the background, while preserving the areas along the axes with relatively small smoothing factors. At least one sample per sample group was analysed in this manner.

\subsection{Thermomagnetic curves}

Measurement of saturation magnetization versus temperature was carried out with the magnetometer ( $\mu$-VSM) from Princeton Measurements Corporation at the IPGP-IMPMC Mineral Magnetism Analytical Facility. A constant field of $0.5 \mathrm{~T}$ was applied during heating to $700{ }^{\circ} \mathrm{C}$ and subsequent cooling at a rate of $10^{\circ} \mathrm{min}^{-1}$. Whenever a curve was irreversible, partial curves were measured with increasing maximum temperatures to identify the temperature at which the magnetic mineralogy changes start taking place.

\subsection{Low-temperature measurements}

Low-temperature magnetization curves were measured with a Magnetic Properties Measurement System from Quantum Design at the Institut de Physique du Globe de Paris. A 2.5 T magnetic field was first applied to samples to acquire a Saturation Isothermal Remanent Magnetization (SIRM) at $300 \mathrm{~K}$ (referred to as $\mathrm{SIRM}_{300 \mathrm{~K}}$ ), then the samples were cooled down to $10 \mathrm{~K}$ in zero-field, and their magnetization was measured during the cooling run. Subsequently, the samples were given another SIRM in a $2.5 \mathrm{~T}$ field at $10 \mathrm{~K}$ (referred to as SIRM $_{10 \mathrm{~K}}$ ), and the samples were warmed up in zero-field to $300 \mathrm{~K}$. The magnetization was measured during the heating run for at least one sample per sample group: eight from Hole U1439C, four from Hole U1440B and four from Hole U1442A.

\subsection{Thellier-Thellier palaeointensities}

\subsubsection{Experimental method}

Palaeointensity determinations were carried out at Géosciences Montpellier in the palaeomagnetism laboratory, following the classical Thellier \& Thellier (1959) method. The samples were heated and cooled twice at each temperature step $T_{\mathrm{i}}$. During the cooling phase, a 35- $\mu \mathrm{T}$ induction field was applied along the cylinder axis of the specimens (z-axis) for the first cycle and in the opposite direction for the second one. Samples were divided into two batches to allow for different heating steps chosen according to the sample thermomagnetic behaviour. The first batch contained the samples with a high $\left(\geq 500{ }^{\circ} \mathrm{C}\right)$ Curie temperature. Thirteen temperature steps up to $610^{\circ} \mathrm{C}$ were carried out with increments of $50{ }^{\circ} \mathrm{C}$ up to $500{ }^{\circ} \mathrm{C}$ and then $25^{\circ} \mathrm{C}$ up to $550^{\circ} \mathrm{C}$ and finally $15^{\circ} \mathrm{C}$ up to $610^{\circ} \mathrm{C}$. The second batch contained the samples dominated by paramagnetic behaviour based on the hysteresis loops and thermomagnetic curves.

Since this second batch also generally had a weaker NRM, heating them together reduced the risk of their magnetization being influenced by stronger samples from the first batch. They were also subjected to 13 heating steps with increments varying between 50 and $15{ }^{\circ} \mathrm{C}$, depending on their thermal behaviour. In order to detect alteration of the TRM spectrum as the laboratory heating temperature is progressively increased, this double-heating protocol is accompanied with a sliding pTRM check procedure (Prévot et al. 1985). The principle is to reinvestigate the pTRM capacity in a given temperature interval after heating to higher temperature. Here we re-measured, throughout the whole experiment, the pTRM intensity acquired in a temperature interval from $\mathrm{T}_{\mathrm{i}-2}$ to room temperature after heating at $T_{\mathrm{i}}$.

All heating-cooling cycles were performed under a vacuum better than $10^{-2} \mathrm{~Pa}$ to limit possible oxidation during the experiment. Each heating-cooling cycle required between 5 and $8 \mathrm{hr}$. The temperature reproducibility between heating runs at the same temperature step 
(a) - Hole 1439C

(b)- Hole 1440B

(c) - Hole 1442A

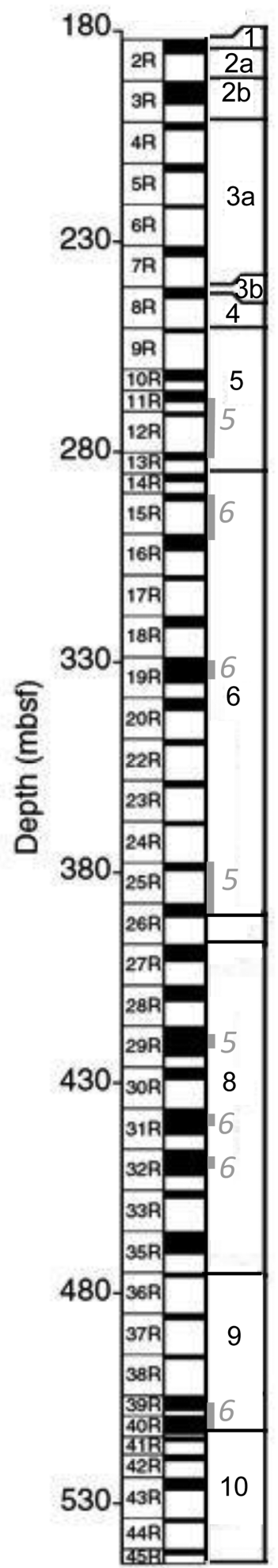

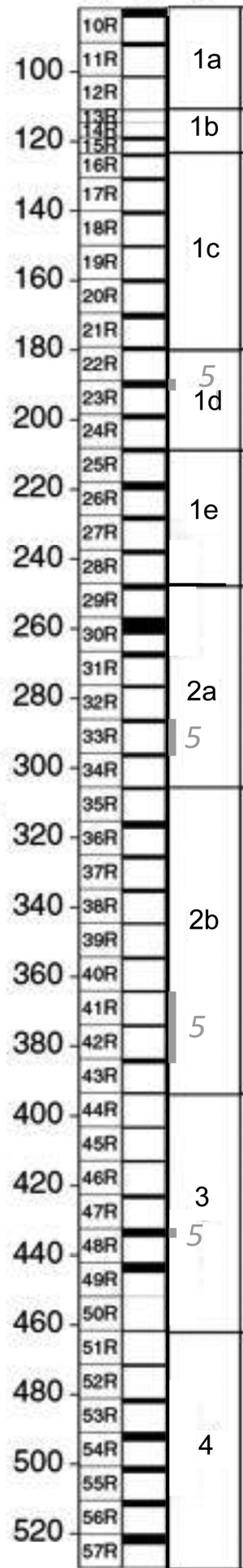

Figure 2. Distribution of sample groups (grey intervals) throughout the stratigraphic sections defined in Reagan et al. (2015b,c,d). The numbers of samples taken in each group are indicated in grey, the unit numbers in black. The black-coloured areas symbolize the recovered fraction of each section of the core.

is within $1{ }^{\circ} \mathrm{C}$. This control is ensured by means of three thermocouples placed at different positions within the heating chamber, plus three others sealed inside three dummy samples. The intensity of laboratory magnetic field is held with a precision better than
$0.1 \mu \mathrm{T}$. The remanence was measured after each heating-cooling cycle at room temperature with a $2 \mathrm{G}$ cryogenic magnetometer. Some samples from the first batch were measured with a JR-5A spinner magnetometer for the last three heating steps because their 
magnetization was too high to be measured with the cryogenic magnetometer. A total of 68 samples were treated by the ThellierThellier method.

\subsubsection{Selection criteria}

The representation and statistical analysis of palaeointensity data were carried out with the ThellierTool software provided by Leonhardt et al. (2004). In this software, the basic statistical parameters are those introduced by Coe et al. (1978) with the modifications proposed by Prévot et al. (1985). This software allows one to interpret the individual palaeointensity data and screen out those of poor quality with the same criteria as those used in Carvallo et al. (2013), which are derived from those of Selkin \& Tauxe (2000) and Leonhardt et al. (2000). These criteria are based on three considerations:

(1) NRM-TRM diagrams (Arai plots). Palaeointensity measurements were represented and analysed with an Arai diagram in which the NRM remaining is plotted against the TRM acquired after each pair of heating experiments (Nagata et al. 1963). The slope of the least-squares-fit line computed from the linear part of these plots gives an estimate of the palaeointensity. A palaeointensity value is rejected when the least squares segment is defined by less than four points $(n<4)$ or it spans less than 30 per cent of the total NRM $(f<0.3)$.

(2) pTRM checks. It is now widely accepted that a linear part on NRM-TRM diagram is not a proof by itself of the absence of alteration in the TRM spectrum during the Thellier experiment, hence the use of pTRM checks. We quantified the difference between two pTRM acquisitions at the same temperature by means of the $\delta_{\mathrm{CK}}$ parameter (Leonhardt et al. 2004), expressed in per cent and corresponding to the maximum difference measured between repeated pTRM acquisition measurements normalized by the intersection of the best fitting line with the pTRM axis. A maximum acceptable threshold is fixed arbitrarily at 6 per cent, which is an intermediate value between the limit values defining Class A and Class B results of Leonhardt et al. (2004).

(3) Vector endpoint diagrams (Zijderveld plots). Directional plots computed from the palaeointensity experiments were checked to ensure that the NRM fraction used to calculate the palaeointensity corresponds effectively to a ChRM. The low-temperature part of the NRM may contain natural secondary magnetizations, and spurious remanent magnetization acquired during laboratory heating may be superimposed on the NRM if chemical changes in the magnetic minerals occurred. This check is achieved qualitatively by a visual inspection of the vector endpoint diagrams obtained during the Thellier-Thellier experiment. The points in the selected interval should trend toward the origin if the NRM is the ChRM. Moreover, the maximum angular deviation (Kirschvink 1980) anchored to the origin of the diagram must be less than $6^{\circ}$ on the selected temperature interval to ensure that the magnetization is stable in direction.

\subsection{Multispecimen palaeointensities}

Absolute intensity determinations of a collection of samples from the three ovens were carried out at the University of Montpellier with the multispecimen (MSP) protocol (Biggin \& Poidras 2006; Dekkers \& Böhnel 2006; Fabian \& Leonhardt 2010). The experiments were performed with a prototype of a very fastheating infrared furnace developed in Montpellier (FURéMAG, patent \#1256194), which has the advantage of heating samples of 10-cc-standard volume very quickly and uniformly. The minicores that were kept for the MSP protocol were furthermore subdivided into 4 or 5 smaller pieces; each piece was then put with a random orientation (i.e. the inclination orientations of the original minicores were not kept) in plaster of Paris to make standard-size minicores. A total of 71 subspecimens have been studied with the MSP domainstate corrected protocol (Fabian \& Leonhardt 2010): 20 from one group from Hole U1439C, and 51 from the four groups from Hole U1440B (12-14 individual samples per group). Thanks to the prototype FURéMAG furnace, a precise magnetic induction field, controlled with a measured precision better than $1^{\circ}$ in direction, was applied to each sample during the heating (and cooling). The heating temperature for the partial thermal remanent magnetization (pTRM) acquisition was chosen between 280 and $450^{\circ} \mathrm{C}$, depending on the thermal behaviour of the samples based on the thermomagnetic curves. This temperature is considered high enough to involve a sufficient fraction of the TRM (at least 20 per cent), but sufficiently low to avoid chemical alteration. In the MSP protocol, the pTRM is imparted along the NRM direction, thus no anisotropy correction is necessary. Moreover, no cooling rate correction is required, as shown by Fanjat (2012).

Before carrying out the experiment, all samples were heated at $100{ }^{\circ} \mathrm{C}$ to erase a possible viscous overprint. The original DekkersBöhnel protocol (referred to as 'DB') involved only one heating steps for each sample, but this protocol was refined by Fabian \& Leonhardt (2010) to add corrections for the NRM fraction $\mathrm{f}$ (referred to as 'FC') and domain state (referred to as 'DSC') with an alpha parameter of 0.5 as recommended in Fabian \& Leonhardt (2010). A second heating step gives access to the NRM fraction and the fraction correction that should decrease the scatter. A third heating allows estimation of the domain state and to correct for the palaeointensity overestimation that has been observed in the case of small PSD grains. Finally, a fourth heating step similar to the first one gives information on the thermal alteration throughout the four heating steps. Moreover, the reliability of the results can be improved by using a set of criteria that are based on the following three considerations:

(1) the fraction of unblocked NRM during the heating steps must be larger than 20 per cent of the total NRM. With this magnitude, the fraction is large enough to be accurately measured;

(2) the maximum angle between the NRM left after the pTRM acquisition and the total NRM is less than $15^{\circ}$;

(3) the relative alteration error $\varepsilon_{\text {alt }}$ (see eq. 19 in Fabian \& Leonhardt 2010) must be $<20$ per cent.

\section{ROCK MAGNETISM MEASUREMENTS-RESULTS}

Various parameters extracted from the following magnetic properties measurements are summarized in Table 1.

\subsection{Hysteresis and FORC diagrams}

Hysteresis parameters of the samples used for this study are presented in Carvallo (2017), together with the parameters for samples throughout the three holes. On a Day-plot, they are scattered below (mostly for samples from Hole U1439C) and slightly above (mostly for samples from Holes U1440B and U1442A) the SD-MD mixing line of Dunlop (2002; Fig. 3). While the hysteresis parameters 
Table 1. Summary of magnetic properties measured on chips from one minicore sample per sample group.

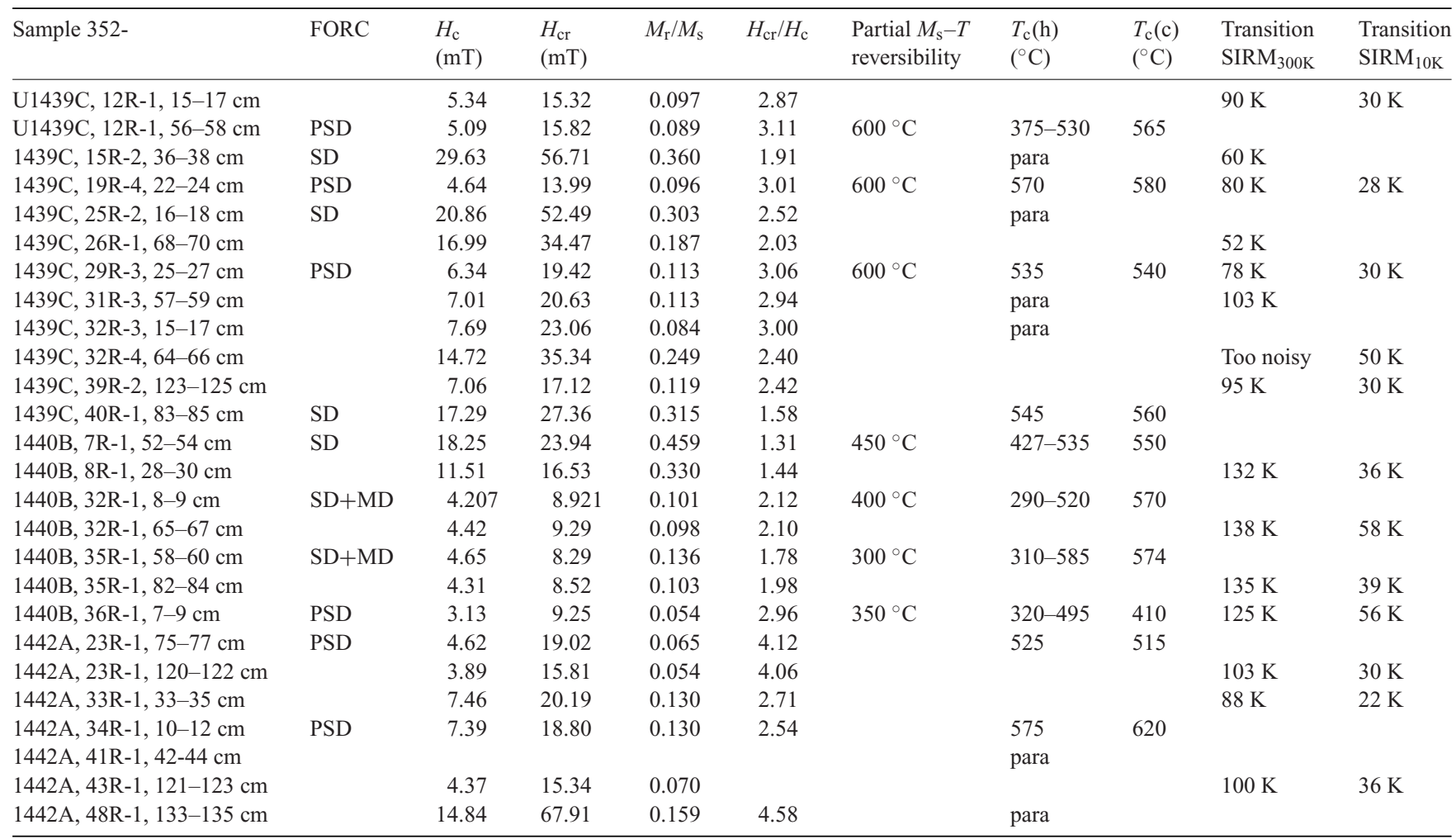

Notes: The sample name is the minicore from the top of which the chip used for the measurement was taken. FORC: main grain size behaviour as identified on FORC diagrams; $H_{\mathrm{c}}$ : coercivity field; $H_{\mathrm{cr}}$ : remanent coercive field; $M_{\mathrm{r}} / M_{\mathrm{s}}$ : ratio of remanent magnetization over saturation magnetization; partial $M_{\mathrm{s}}-T$ reversibility: maximum temperature for which the partial thermomagnetic $\left(M_{\mathrm{S}}-T\right)$ curve is reversible, measured whenever the full $M_{\mathrm{s}}-T$ curve was not reversible; $T_{\mathrm{c}}(\mathrm{h})$ : Curie temperature determined from the second derivative of the $M_{\mathrm{s}}-T$ curve as the maximum curvature point, for the heating curve. 'para' means that the magnetic behaviour is mostly paramagnetic and therefore a Curie temperature could not be determined; $T_{\mathrm{c}}(\mathrm{c})$ : same, but for the cooling curve; Transition $\mathrm{SIRM}_{10 \mathrm{~K}}$ : transition temperature corresponding to the maximum curvature point in the $\mathrm{SIRM}_{10 \mathrm{~K}}$ heating curve; Transition SIRM $300 \mathrm{~K}$ : same, but for the SIRM $_{300 \mathrm{~K}}$ cooling curve.

for some sample groups are very similar, other groups show very inhomogeneous hysteresis parameters.

(1) Hole U1439C. Three main behaviours can be identified. For three out of the eight sample groups, the FORC diagrams are characteristic of PSD grains, with outermost contours diverging away vertically from the origin of the diagram, and contours extending to about $60 \mathrm{mT}$ horizontally (Fig. 4a). In one group, the FORC diagram is more SD-like, with almost all the contours being closed around a maximum value of $20 \mathrm{mT}$ and contours that go as far as $80 \mathrm{mT}$ on the coercivity distribution scale (Fig. 4b). A secondary peak is present close to the origin, and is probably caused by an MD component rather than an SP one, because the contours parallel to $H_{\mathrm{c}}=0$ extend into the positive part of the diagram (Fig. 4b). After removal of the small paramagnetic component, the saturation magnetization of samples that have these two characteristic behaviours is usually between 0.2 and $0.9 \mathrm{Am}^{2} \mathrm{~kg}^{-1}$. Four other samples from this hole display a different behaviour (Fig. 4c): hysteresis loops reveal a strong paramagnetic component, and the ferromagnetic saturation magnetization is much weaker, of the order of a few $\mathrm{mAm}^{2} \mathrm{~kg}^{-1}$. As a consequence, FORCs were sometimes too noisy to obtain a meaningful FORC diagram. Nevertheless, this ferromagnetic contribution seems to be carried by SD grains, as indicated by the strong coercivity (Fig. 4c) and the closed-contours of FORC diagrams.

(2) Hole U1440B. As with Hole U1439C samples, three different behaviours can be identified with the FORC diagrams. One sample
(Fig. 4e) has a diagram that is characteristic of SD grains, with a very small SP or MD component. Unlike the SD samples from Hole $\mathrm{U} 1439 \mathrm{C}$, this one does not have a strong paramagnetic component. The ferromagnetic saturation magnetization of samples from this unit is around $0.4-0.5 \mathrm{Am}^{2} \mathrm{~kg}^{-1}$. Two samples clearly display two separated components, one SD and one MD (Fig. 4f), as shown by the two separated peaks. Finally, one sample is more PSD-like, showing only one component and only a few of the inner contours that are closed, while the other contours diverge vertically (Fig. 4f). These samples are all strongly magnetized $\left(1-2 \mathrm{Am}^{2} \mathrm{~kg}^{-1}\right)$.

(3) Hole U1442A. Samples from Hole U1442A display the same two behaviours as in Hole U1449C, which was not surprising because the two holes were drilled very close to one another and the sample compositions are similar. Two samples were PSD-like (Fig. 4g) while the other two had a ferromagnetic component so small that FORC diagrams could not be easily measured. However, hysteresis parameters indicate that the magnetization carriers are SD (Carvallo 2017). As for samples from Hole U1449C, there is one or two orders of magnitude difference in the saturation magnetizations between these two magnetic behaviours, showing that the magnetic mineralogy is very variable downhole.

\subsection{Thermomagnetic curves}

The different types of thermomagnetic curves are well correlated with the different kinds of FORC diagrams. 


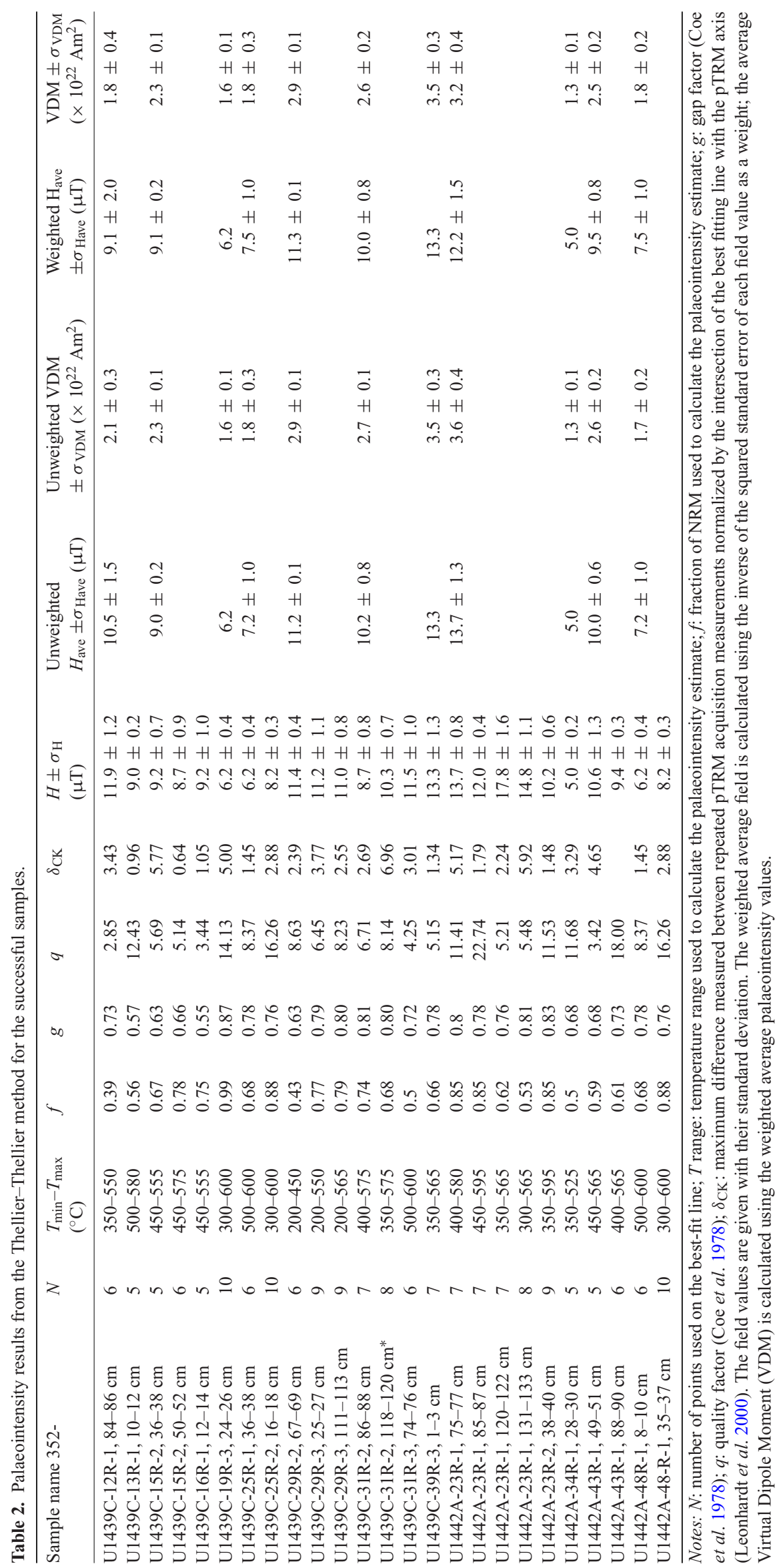




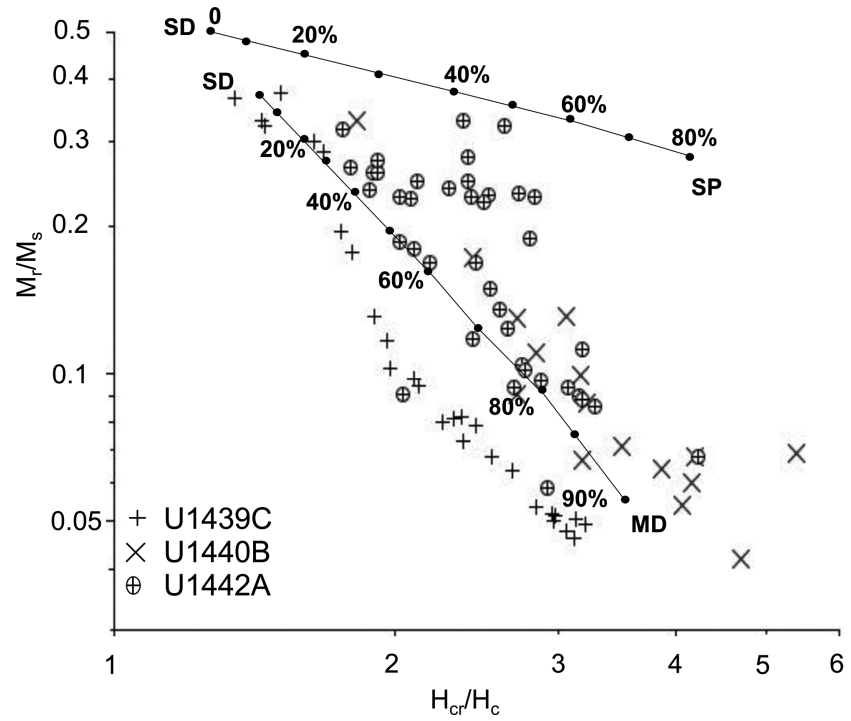

Figure 3. Day-plot (the ratio of remanent to saturation magnetization, $M_{\mathrm{r}} / M_{\mathrm{S}}$ versus the ratio of remanent coercivity to coercivity, $H_{\mathrm{cr}} / H_{\mathrm{c}}$ ) for sister samples used for palaeointensity determinations, with the SD-SP and SD-MD mixing lines of Dunlop (2002) for comparison.

(1) Hole U1439C. Samples that were characterized by PSD-like FORC diagrams have almost reversible thermomagnetic curves (Figs 5a-c) and Curie temperatures (temperature at which the curvature is maximum) between 530 and $580{ }^{\circ} \mathrm{C}$. This indicates the presence of low-Ti titanomagnetite (Hunt et al. 1995). Some samples show a very small secondary Curie temperature around $375{ }^{\circ} \mathrm{C}$ (indicated by a very small inflexion point on the curve) that could indicate the presence of a small amount of pyrrhotite or higher-Ti titanomagnetite (Fig. 5a). For samples that had a strong paramagnetic component on the hysteresis loop, the thermomagnetic curve only shows the reversible decrease with temperature of this paramagnetic magnetization (Fig. 5d). The ferrimagnetic contribution is therefore not visible here. In order to identify only the ferromagnetic component, we measured a susceptibility versus $T(k-T)$ curve for this sample (352, U1439C, 25R-2, 16-18 cm). The curve was acquired at low-temperature by means of a cryostat apparatus (CS-L) and at high-temperature under Argon by means of a furnace (CS-3) coupled to the KLY-3 Kappabridge instrument (AGICO, Czech Republic) at the University of Montpellier. The sample was first heated from the liquid nitrogen temperature $(-194$ $\left.{ }^{\circ} \mathrm{C}\right)$ to about $650{ }^{\circ} \mathrm{C}$ and cooled down to room temperature. The data were corrected for the empty holder. The low-temperature curve confirms the importance of the paramagnetic component, but the high-temperature curve allows us to identify the main magnetization carrier as low-Ti titanomagnetite (Fig. $5 \mathrm{j}$ ). The $k-T$ curve is quite reversible.

(2) Hole $U 1440 B$. The thermomagnetic curves from Hole U1440B samples all show irreversibility to various degrees between the warming and the cooling curve (Figs 5e-i). Sample 352-U1440B-7R1, 52-54 cm which displayed SD behaviour on FORC measurements, has a Curie temperature close to $430{ }^{\circ} \mathrm{C}$, upon cooling (after heating to $700{ }^{\circ} \mathrm{C}$ ) the newly formed carrier of the magnetization has a saturation magnetization that is almost three times stronger than the starting mineral and a Curie

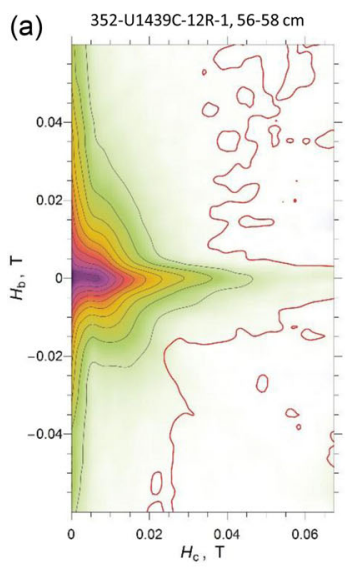

(d)

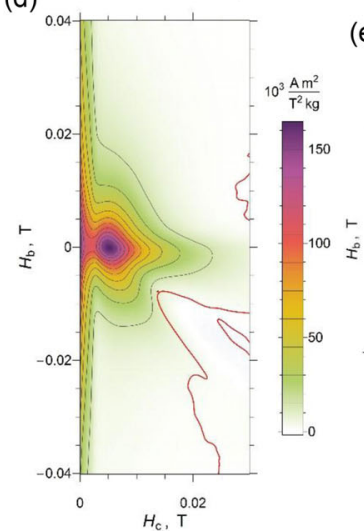

(b) 352-U1439C-40R-1, 83-85 cm

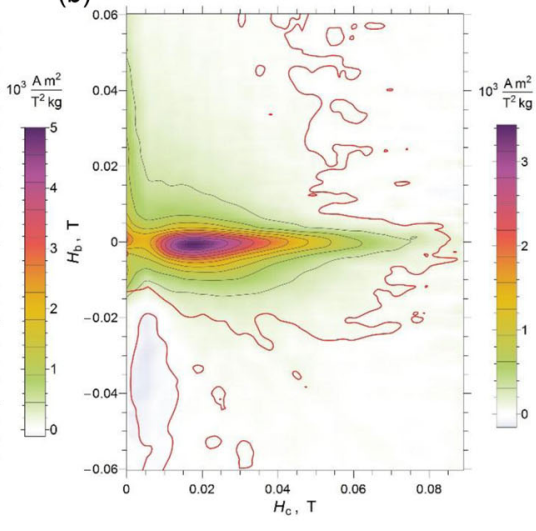

(e) $\quad 352-U 1440 B-7 R-1,52-54 \mathrm{~cm}$

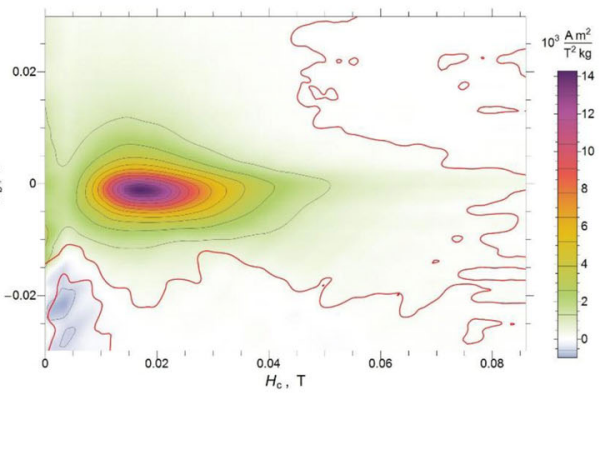

(C) $352-U 1439 \mathrm{C}-15 \mathrm{R}-2,36-38 \mathrm{~cm}$

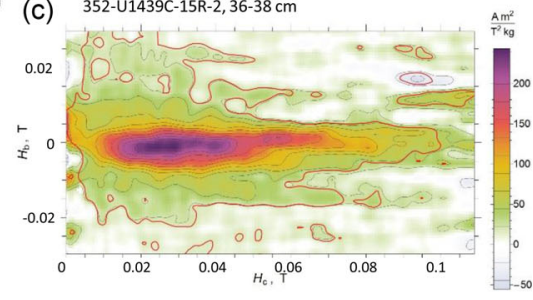

Figure 4. Examples of FORC diagrams for representative samples from the three holes, calculated from 200 individual FORCs with the VARIFORC software (Egli 2013) and measured with an averaging time of 0.1 or $0.2 \mathrm{~s}$. 
temperature of $550{ }^{\circ} \mathrm{C}$ (Fig. 5e). Partial thermomagnetic curves are quite reversible up to $450{ }^{\circ} \mathrm{C}$ (Fig. 5f). It is possible that the irreversibility is caused by the alteration of titanomaghemite into low-Ti titanomagnetite+ilmenite. The two samples that showed a mixture of SD+MD behaviour on the FORC diagrams are also characterized by strongly irreversible curves, with a Curie temperature around $300{ }^{\circ} \mathrm{C}$ from grains that are transformed into magnetite with subsequent heating. This Curie temperature is still present upon cooling (Fig. 5g). This irreversibility could indicate the presence of unstable titanomaghemite. Finally, the more PSD-like sample
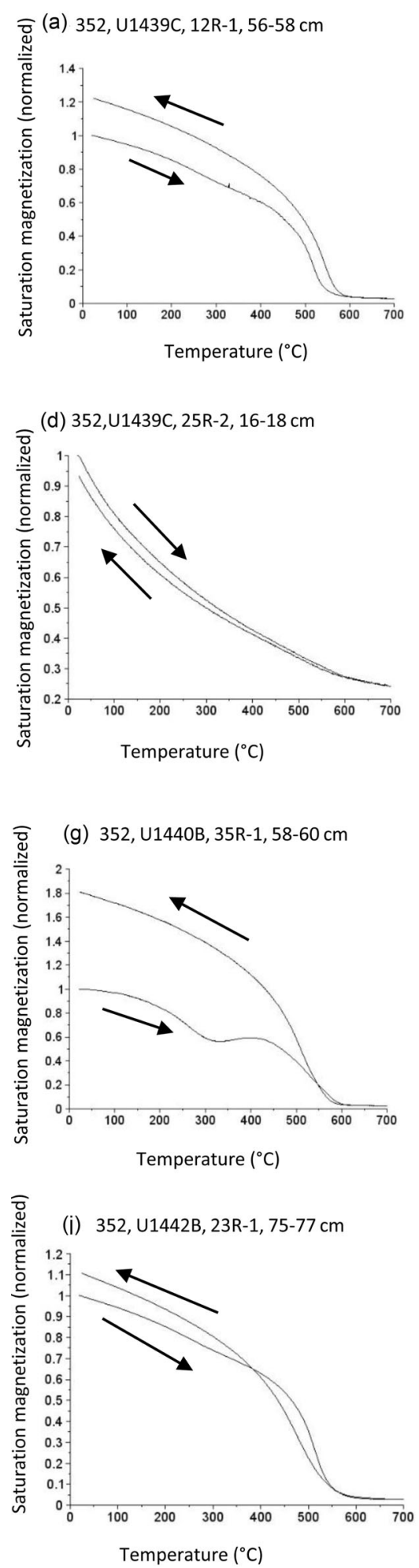

(b) $352, \mathrm{U} 1439 \mathrm{C}, 12 \mathrm{R}-1,56-58 \mathrm{~cm}$

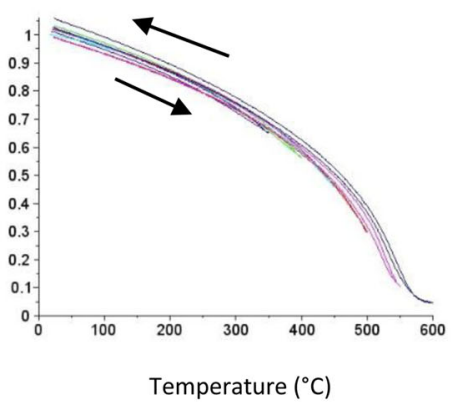

(e) $352, \mathrm{U} 1440 \mathrm{~B}, 7 \mathrm{R}-1,52-54 \mathrm{~cm}$

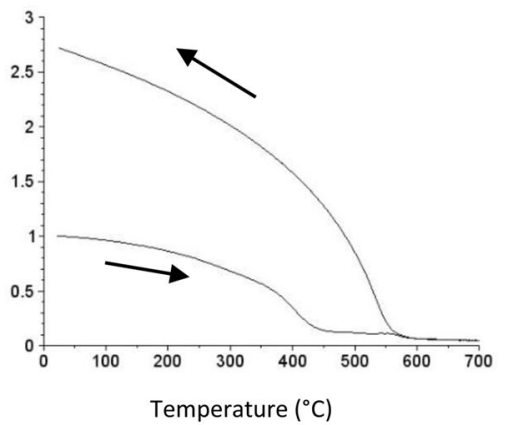

(g) 352, U1440B, 35R-1, $58-60 \mathrm{~cm}$

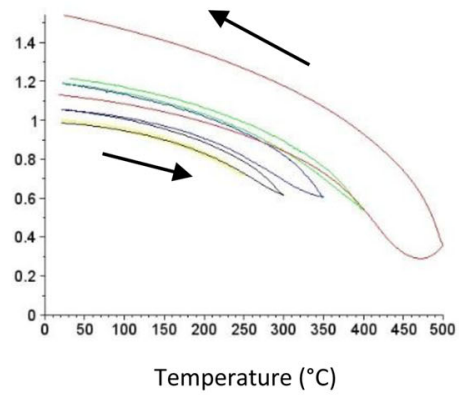

(j) $352, U 1439 \mathrm{C}, 25 \mathrm{R}-2,16-18 \mathrm{~cm}$

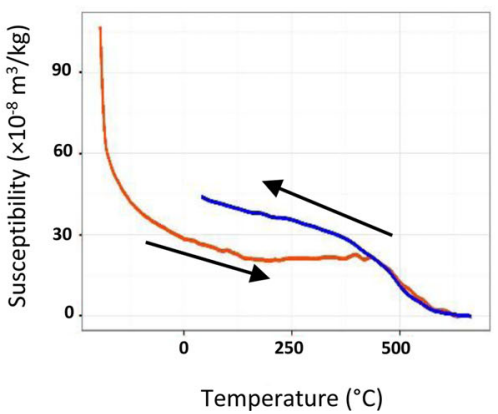

(c) 352, U1439C, $40 \mathrm{R}-1,83-85 \mathrm{~cm}$

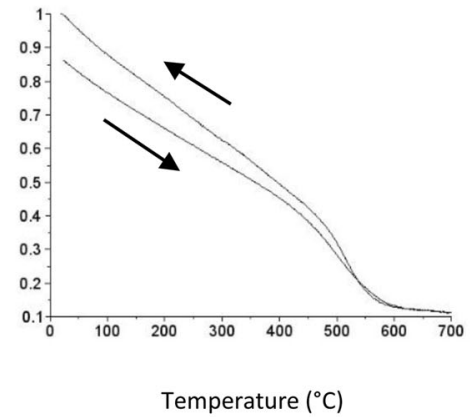

(f) $352, \mathrm{U} 1440 \mathrm{~B}, 7 \mathrm{R}-1,52-54 \mathrm{~cm}$

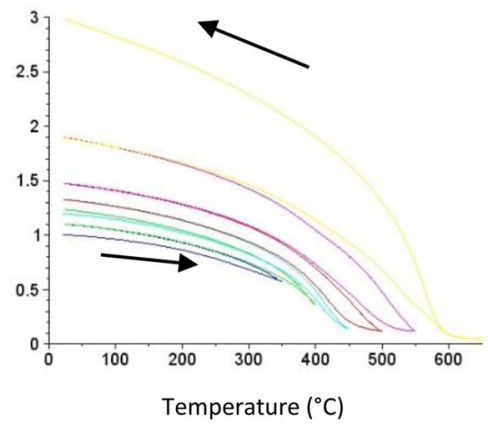

(h) $352, \mathrm{U} 1440 \mathrm{~B}, 36 \mathrm{R}-1,7-9 \mathrm{~cm}$

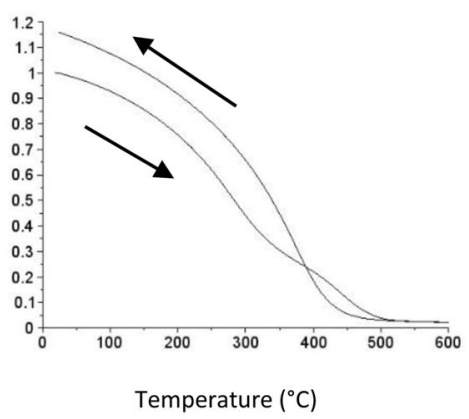

(k) $352, \mathrm{U} 1442 \mathrm{~B}, 48 \mathrm{R}-1,133-135 \mathrm{~cm}$

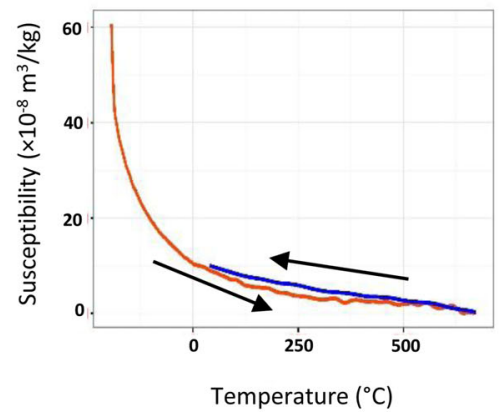

Figure 5. (a-i) Examples of thermomagnetic $\left(M_{\mathrm{s}}-T\right.$ : saturation magnetization versus temperature) curves for representative samples from the three holes. For samples with irreversible curves, partial curves were also measured ( $\mathrm{b}, \mathrm{f}, \mathrm{g})$. ( $\mathrm{j}-\mathrm{k}) k-T$ (susceptibility versus temperature) curve for two samples for which the $M_{\mathrm{s}}-T$ curve only shows the paramagnetic component. 
(a) $352, \mathrm{U} 1442 \mathrm{~B}, 23 \mathrm{R}-1,75-77 \mathrm{~cm}$

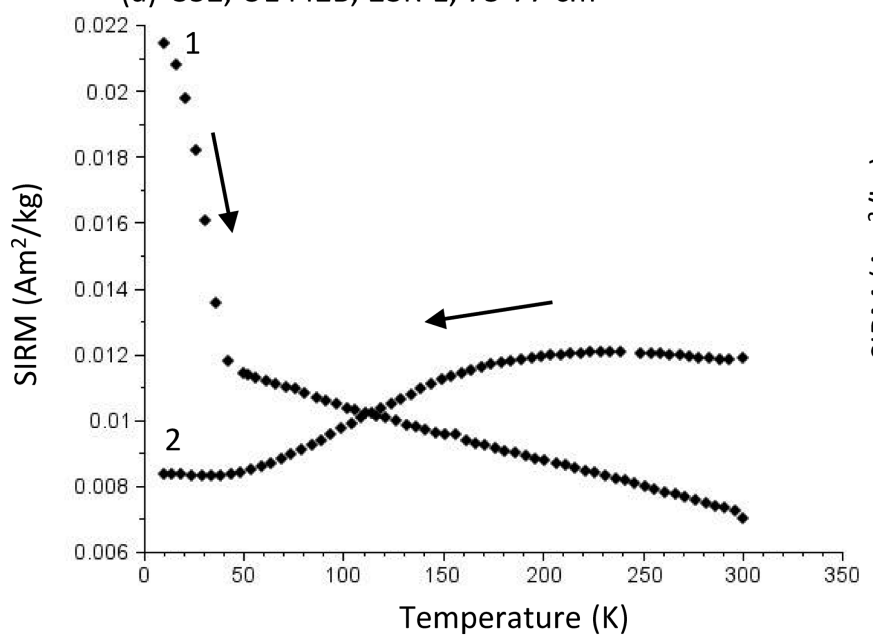

(c) $352, \mathrm{U} 1440 \mathrm{~A}, 35 \mathrm{R}-1,82-84 \mathrm{~cm}$

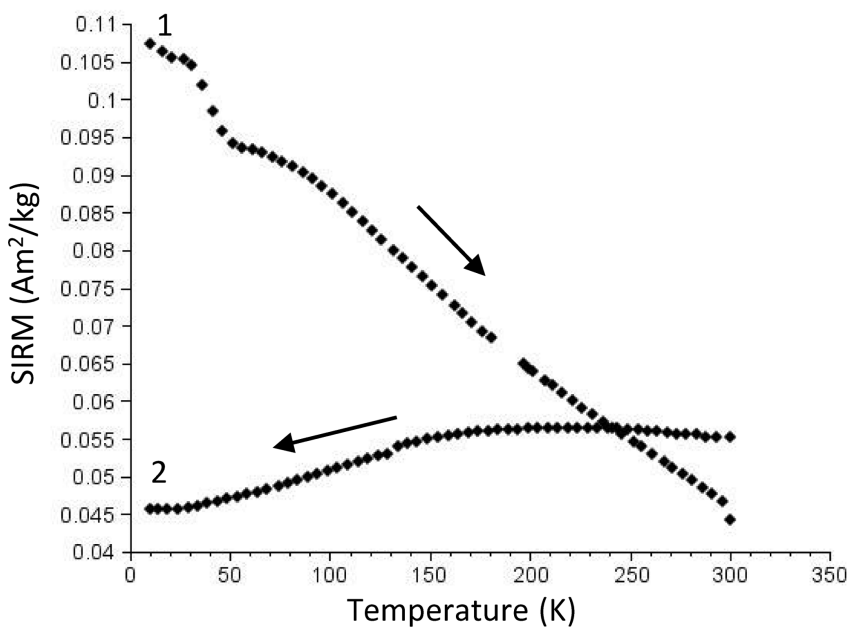

(b) $352, \mathrm{U} 1439 \mathrm{C}, 26 \mathrm{R}-1,68-70 \mathrm{~cm}$

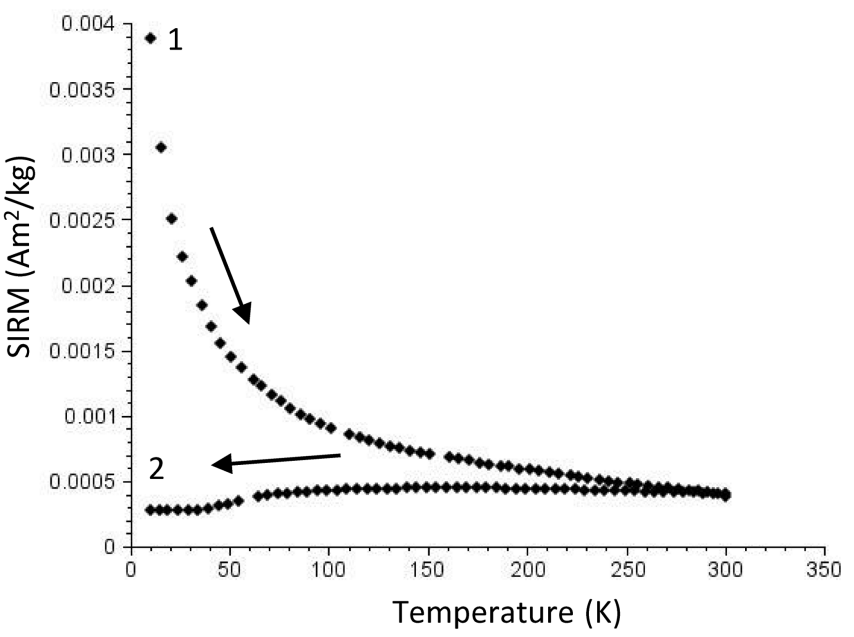

(d) 352, U1440A, 32R-1, 65-67 cm

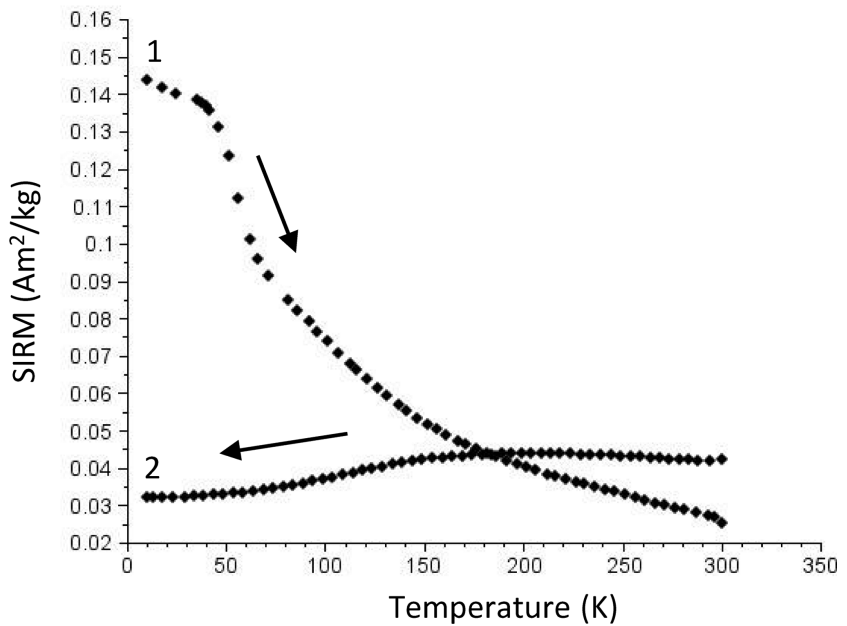

Figure 6. Examples of low temperature dependence of saturation remanence (SIRM) produced by a $2.5 \mathrm{~T}$ field. The curves labelled ' 1 ' show the zero-field warming curve from 20 to $300 \mathrm{~K}$. The curves labelled ' 2 ' show the zero-field cooling ( 300 to $20 \mathrm{~K}$ ) curve for SIRM produced at $300 \mathrm{~K}$.

also shows this mineralogical change but in a smaller proportion (Fig. 5h). However, a first Curie temperature around $320^{\circ} \mathrm{C}$ is visible, followed by another drop around $500{ }^{\circ} \mathrm{C}$.

(3) Hole U1442A. Unsurprisingly, because of the identical lithology, we observe the same two behaviours as for the samples from Hole U1439C. Two out of four flows have nearly reversible thermomagnetic curves with Curie temperatures between 525 and $575{ }^{\circ} \mathrm{C}$ (Fig. 5i), indicating the presence of low-Ti titanomagnetite, while the other two have paramagnetic curves (similar to Fig. 5d), in a correlated way with the hysteresis and FORC measurements. A small secondary $T_{\mathrm{c}}$ at $250{ }^{\circ} \mathrm{C}$ could be identified on the curves of the Fig. 5 i type. A $k-T$ curve similarly to the curve measured for the sample 352, U1439C, 25R-2, 16-18 cm also shows only a paramagnetic component (Fig. 5k).

\subsection{Low-temperature measurements}

The different observed behaviours from low-temperature measurements correlate well with the previous measurements (FORC diagrams and thermomagnetic curves) (Table 1). In Holes U1439C and U1442A, the samples with reversible thermomagnetic curves and PSD FORC diagrams show a broad decrease during the cooling of SIRM $_{300 \mathrm{~K}}$ (Fig. 6a), which could be identified as a Verwey transition, even though the point of maximum curvature is lower than $120 \mathrm{~K}$, the Verwey temperature for magnetite. This low Verwey temperature confirms the presence of low-Ti titanomagnetite (Moskowitz et al. 1998). The $\mathrm{SIRM}_{300 \mathrm{~K}}$ at $10 \mathrm{~K}$ is about one third of that at $300 \mathrm{~K}$. When heated to $300 \mathrm{~K}$, the $\mathrm{SIRM}_{10 \mathrm{~K}}$ decreases to one-third of its initial value with a more-or-less abrupt break in slope that occurs around $30-40 \mathrm{~K}$. The same behaviour was observed by Moskowitz et al. (1998) in synthetic titanomagnetite with Ti content lower than 30 per cent. In contrast, the samples for which the magnetic properties are dominated by paramagnetism have a completely different behaviour (Fig. 6b): at low temperature $(<100 \mathrm{~K})$ the SIRM $_{10 \mathrm{~K}}$ decreases very sharply, which is representative of the decrease of the induced paramagnetic signal that results from a small, residual field in the MPMS. The SIRM ${ }_{300 \mathrm{~K}}$ curves for the same samples are almost constant when cooled down to $10 \mathrm{~K}$, except for a very small change in SIRM that occurs between $60 \mathrm{~K}$ and $100 \mathrm{~K}$ in some samples, perhaps corresponding to the presence of chromite (Gattacceca et al. 2011; Fig. 6b).

The four samples from Hole U1440A can be classified in two similar groups. For one of the groups, the $\mathrm{SIRM}_{300 \mathrm{~K}}$ cooling curve shows a very small drop at $125-130 \mathrm{~K}$ followed by a nearly linear 
decrease of the magnetization to about 80 per cent (Fig. 6c). When heated, the $\mathrm{SIRM}_{10 \mathrm{~K}}$ decreases through a small transition between 35 and $40 \mathrm{~K}$ and then decreases almost linearly between 100 and $300 \mathrm{~K}$ to reach a value about 40 per cent of the original low-temperature SIRM. This small transition could be caused by the presence of ilmenite (Ishikawa 1962). The rest of the SIRM demagnetization curve has the same shape as that of synthetic titanomagnetite of composition $x=0.6$ (Moskowitz et al. 1998). Samples from the second group have $\mathrm{SIRM}_{300 \mathrm{~K}}$ cooling curves with the same characteristics as those from the first group (small decrease broadly distributed around $125-140 \mathrm{~K}$ ), but the $\mathrm{SIRM}_{10 \mathrm{~K}}$ heating curves show a transition around $56-58 \mathrm{~K}$ that is more marked than for the first group samples (Fig. 6d). At $300 \mathrm{~K}$, the $\mathrm{SIRM}_{10 \mathrm{~K}}$ is only about 20 per cent of its value at $10 \mathrm{~K}$.

\section{PALAEOINTENSITY DETERMINATIONS RESULTS}

Because of the different magnetic properties of the samples, we chose to use two different methods for the palaeointensity determinations: the Thellier-Thellier method and the MSP method (Fabian \& Leonhardt 2010; Monster et al. 2015). Each of them has advantages and disadvantages and different requirements. Samples from seven out of the eight groups taken from Hole U1439C have a reversible thermomagnetic curve and PSD-like FORC diagrams, therefore the Thellier-Thellier method can be applied to them. The samples from the last group from Hole U1439C are less reversible on the thermomagnetic curve and were measured with the MSP, which does not require so many heating steps and SD or PSD grain size, except one sample from that group that was measured also with the Thellier-Thellier batch for comparison. Samples from all the sample groups from Hole U1440B had a non-reversible thermomagnetic curve, so they also were destined for the MSP treatment, save one sample per group that also were measured with the Thellier-Thellier routine. Finally, all the specimens from Hole U1442B had characteristics to be potentially successful with the Thellier-Thellier method, so it was used.

\subsection{Thellier-Thellier method}

Out of the 68 samples, 25 gave results that appear reliable (Fig. 7). Successful results are presented in Table 2. The main reasons for failure were concave Arai plots and nonlinear Zijderveld plots (Fig. 8). The eight samples from Hole U1440B failed because of erratic Arai plots. Fifteen out of 40 samples from Hole U1439C and 10 out of 20 samples from Hole U1442A satisfied our set of selection criteria. One of the samples (marked in Table 2 with an asterisk) had a $\delta_{\mathrm{CK}}$ value slightly over the chosen criterion, but the other criteria were within acceptance range and the palaeointensity value is in good agreement with the other values from the same group. The top-most and the bottom-most sample groups of Hole U1439C show evidence of a partial self-reversal of magnetization (Fig. 7a), as is true of samples from two groups from Hole U1442A. Such behaviour had been observed on the thermal demagnetizations carried out on-board (Reagan et al. 2015b). Most samples carried a secondary magnetization that was erased by heating to $350-400{ }^{\circ} \mathrm{C}$, then the NRM was quite sharply demagnetized between 550 and $600{ }^{\circ} \mathrm{C}$. This confirms the presence of fine grain titanomagnetite with very little titanium as a main magnetization carrier in the successful samples. Drilling induced magnetization that is sometimes present in IODP samples was never a problem to the point of causing the failure of any palaeointensity measurements, possibly because of the high coercivity of the magnetization carriers (Reagan et al. 2015 b,c,d). Palaeointensity values extracted from these successful samples typically give consistent values within one group. It is interesting to note that all the samples from a particular group did not always show similar behaviour in terms of unblocking temperature spectra or linearity or concavity of the Arai plot. Weighted average values using the inverse of the squared standard error of each field value as a weight, together with the error on the average (Coe et al. 1978), were calculated for each group.

\subsection{Multispecimen method}

Results are summarized in Table 3. Out of the 20 samples from Hole U1439C, the DSC-MSP protocol (producing 13 accepted samples) leads a palaeointensity value of $15.1 \mu \mathrm{T}$ with a 65 per cent confidence interval of [13.5-18.7] $\mu \mathrm{T}$ (Fig. 9a). The results for the groups from Hole U1440B are of poor quality: for two of them, too few samples pass the selection criteria and the scatter on the Q-plot is too important to define a palaeointensity with a reasonable 65 per cent confidence interval. The other two also show significant scatter, but nevertheless it is possible to extract a MSP-DSC value from these data sets (Figs $9 \mathrm{~b}$ and $\mathrm{c}$ ). They both give identical palaeointensity values of $20.8 \mu \mathrm{T}$ with a confidence interval of [18.1-24.5] $\mu \mathrm{T}$ and [14.9-24.6] $\mu \mathrm{T}$, respectively. The main reason for failure of these samples is probably related to the irreversibility with heating that was observed with on the thermomagnetic curves, and to the presence of a secondary component of magnetization in the limited temperature range that we used to avoid alteration with heating.

\section{DISCUSSION}

\subsection{Magnetic properties}

Samples from the two holes drilled into mostly boninites (Holes U1439C and U1442A) have two very distinct behaviours:

(1) Magnetic properties that are characteristic of a small amount of ferromagnetic mineral in a large paramagnetic component; the paramagnetism dominates both the low- and high-temperature magnetization curves.

(2) A behaviour characteristic of low-Ti titanomagnetite, with a PSD-SD grain size and a SIRM IOK $_{10}$ warming curve with a break-inslope.

Samples with the first kind of behaviour come from igneous rocks identified as boninite by the shipboard petrologists, while samples with the second kind of behaviour come from sections identified as andesites (bottom-most part of the Hole) or boninites where significant alteration occurred, resulting also in high magnetic susceptibility values (Reagan et al. 2015a). The Thellier-Thellier success rate is slightly higher for andesites (41 per cent) than from boninites ( 36 per cent), but the palaeointensity values are similar for both mineralogies. It is also interesting to note that there is apparently no correlation between the hysteresis parameters and the success or failure of the corresponding sister sample (de Groot et al. 2012).

The magnetic properties of samples from Hole U1440B are very different from the other two holes. They are also petrologically distinct from Holes U1439C and U1442A because most igneous rocks from this hole are forearc basalts (Reagan et al. 2015a). 

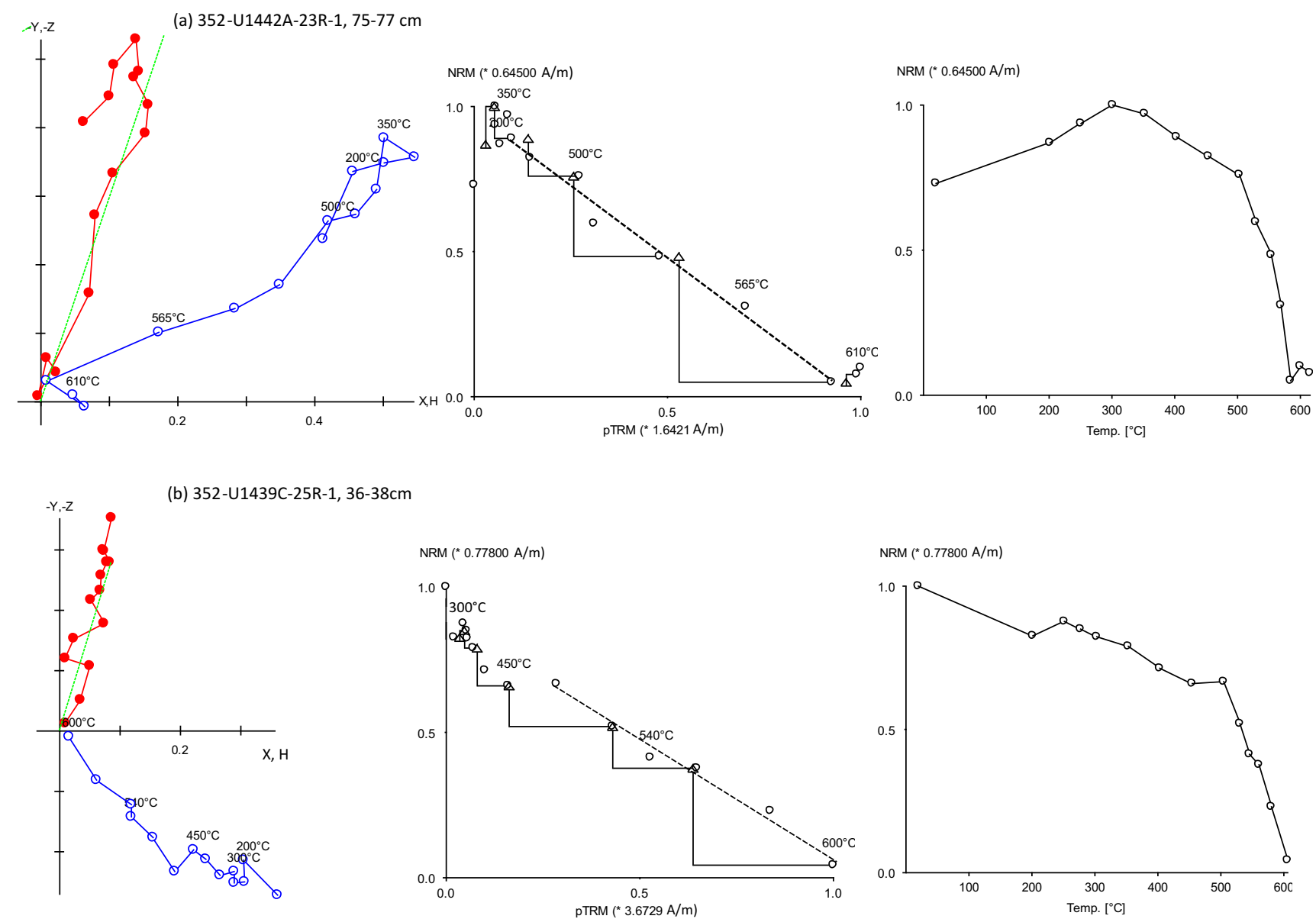

Figure 7. Examples of Zijderveld diagrams, Arai plots and demagnetization spectra for 2 samples that give reliable palaeointensity determinations. (a) Sample 352-U1442A-23R-1, 75-77 cm; (b) Sample 352-U1439C-21R-1, 36-38 cm. Three plots are shown for each sample. The Zjiderveld (orthogonal vector) plots (left) show magnetization vector endpoints projected on horizontal and vertical planes at each demagnetization step. Full symbols indicate the projection on the vertical plane whereas open symbols indicate the horizontal plane. The Arai plot (middle) shows the normalized amount of magnetization, pTRM, acquired at each heating step. Demagnetization spectra plots (right) show the normalized amount of magnetization intensity remaining after each demagnetization step.

352-U1439C-16R-1, 53-55 cm
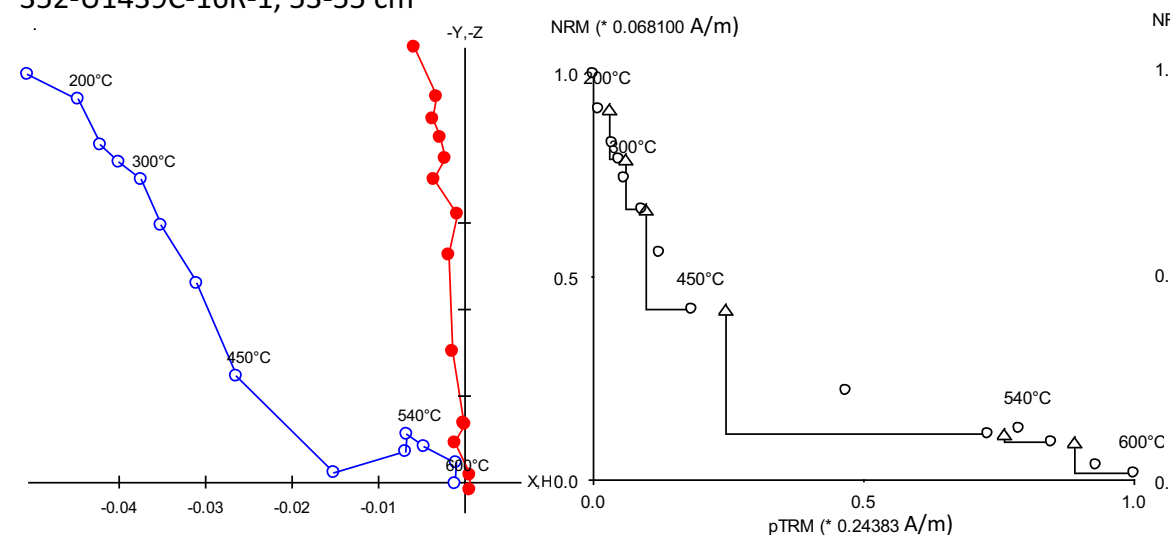

NRM $\left({ }^{*} 0.068100 \mathrm{~A} / \mathrm{m}\right)$

Figure 8. Example of a Zijderveld diagram, Arai plot and demagnetization spectrum for a sample (352-U1439C-16R-1, 53-55 cm) that did not give a reliable palaeointensity result. The Zijderveld plot did not define a characteristic remanent magnetization; moreover, the Arai plot is strongly concave-upward. 
Table 3. Palaeointensity results from the multispecimen (MSP) method.

\begin{tabular}{|c|c|c|c|c|c|c|c|}
\hline Sample group & Method & $\mathrm{PI}(\mu \mathrm{T})$ & $65 \%$ conf & $n / N$ & $R$-squared & VDM & VDM $65 \%$ confidence \\
\hline \multirow[t]{3}{*}{$352-\mathrm{U} 1439 \mathrm{C}-19 \mathrm{R}-2$ to $19 \mathrm{R}-4 \mathrm{act}$} & DB & 15.2 & [13.5-16.9] & $19 / 20$ & 0.8448 & 3.9 & {$[3.5-4.3]$} \\
\hline & FC & 11.7 & {$[9.9-13.1]$} & $13 / 20$ & 0.8668 & 3.0 & {$[2.5-3.4]$} \\
\hline & DSC & 15.1 & [13.5-18.7] & $13 / 16$ & 0.8455 & 3.9 & {$[3.5-4.8]$} \\
\hline \multirow[t]{3}{*}{ 352-U1440B-6R-1 to 8R-1 } & DB & 28.1 & {$[25.9-29.8]$} & $14 / 16$ & 0.7982 & 7.2 & {$[6.6-7.6]$} \\
\hline & FC & n.d. & & & & & \\
\hline & DSC & 26.1 & {$[3.3-38.4]$} & $4 / 8$ & 0.8443 & 6.7 & {$[0.8-9.8]$} \\
\hline \multirow[t]{3}{*}{ 352-U1440B-32R1 } & DB & n.d. & & & & & \\
\hline & $\mathrm{FC}$ & n.d. & & & & & \\
\hline & DSC & 20.8 & [18.1-24.5] & $3 / 11$ & 0.8074 & 4.8 & {$[4.2-5.8]$} \\
\hline \multirow[t]{3}{*}{ 352-U1440B-35R-1 } & DB & n.d. & & & & & \\
\hline & $\mathrm{FC}$ & 25.0 & {$[16.6-30.6]$} & $9 / 11$ & 0.7308 & 4.9 & {$[3.3-6.0]$} \\
\hline & DSC & 20.8 & [14.9-24.6] & $8 / 11$ & 0.8157 & 4.1 & {$[2.9-4.9]$} \\
\hline \multirow[t]{3}{*}{ 352-U1440B-36R-1 } & DB & 9.7 & {$[6.3-14.4]$} & $13 / 14$ & 0.8109 & 1.9 & {$[1.2-2.9]$} \\
\hline & $\mathrm{FC}$ & n.d. & & & & & \\
\hline & DSC & n.d. & & & & & \\
\hline
\end{tabular}

Notes: The MSP values are estimated by the zero-crossing point of the linear regression on the $Q$ parameters obtained with the MSP-DB protocol (Dekkers \& Böhnel 2006), fraction correction (MSP-FC) or domain state correction protocols (MSP-DSC) (Fabian $\&$ Leonhardt 2010) as a function of the laboratory field. $R$-squared: coefficient of determination indicating how well data fit the model; $n / N$ : number of samples selected for the fit/total number of samples.

They all show some evidence of the presence of ilmenite in various quantities, however the magnetic signal is most likely carried by high-Ti titanomagnetite (-maghemite), with various degrees of reversibility on the thermomagnetic curves. Grain sizes range from SD to mixtures of SD-MD. Changes in mineralogy during heating are the reason why the Thellier-Thellier experiments failed on these rocks and MSP gave poor quality results: the temperature range below which mineralogical changes occurred was too short to affect a large enough fraction of the NRM to produce reliable results.

\subsection{VDM values}

Palaeointensity values must be converted into VDM to be compared with data from other locations, using the inclination measured at the sampling site. Directions obtained from the palaeointensity experiments show a large scattering, and the averaging from this sample set is not sufficient. Therefore, we prefer to use inclinations measured by thermal and alternating-field demagnetizations onboard the JOIDES Resolution during the Expedition (Reagan et al. $2015 \mathrm{a}, \mathrm{b}, \mathrm{c}, \mathrm{d}$ ) and on-shore at the University of Houston (Sager et al. 2017). Inclinations measured on the same part of core than each sample group were averaged with the inclination-only statistics of McFadden \& Reid (1982). For Hole U1439C, the Thellier-Thellier method leads to average VDM values for each sample group that are between 1.6 and $3.5 \times 10^{22} \mathrm{Am}^{2}$. The two most extreme values are from groups where only one sample gave a reliable palaeointensity value, suggesting problematic lithologies. Without these two values, the average VDMs are $1.8 \pm 0.1$ and $2.9 \pm 0.1 \times 10^{22}$ $\mathrm{Am}^{2}$. The VDM result of $3.9 \times 10^{22} \mathrm{Am}^{2}$ (65 per cent confidence interval of [3.5-4.8] $\times 10^{22} \mathrm{Am}^{2}$ ) obtained from the MSP method is higher than this range. The VDM values for samples from Hole U1442A are in the range $1.3-3.3 \times 10^{22} \mathrm{Am}^{2}$ but this range decreases to $1.9-3.3 \times 10^{22} \mathrm{Am}^{2}$ when we ignore the sample group for which only one sample gave a reliable Thellier-Thellier result. These results are consistent with the Thellier-Thellier results from Hole U1439C, which we expected since volcanic rocks from both holes are boninites and related rocks, therefore have similar origins and probably erupted around the same period.

No reliable Thellier-Thellier data were produced for Hole U1440B, and the MSP method led only poor quality results for two groups, a result with a very large uncertainty for another group and no result at all for the last group. After corrections for fraction and domain state, final VDM values from two groups of samples that gave a result are between 4.1 and $4.8 \times 10^{22} \mathrm{Am}^{2}$. These values are higher than the values obtained for the other holes.

We can compare this value with other values obtained with the Thellier-Thellier method, gathered from the PINT database (Biggin et al. 2010), using whole rocks, submarine basaltic glass and single plagioclase crystals. Our data are plotted together with other VDM values between 29 and $69 \mathrm{Ma}$ (Fig. 10). We used the dates provided by Ishizuka et al. (2011) and Reagan et al. (2013), but new dates will be measured on some of the Exp. 352 rocks in the future. Nevertheless, our VDM data fill a blank in a time region in which only two studies exist. Our Thellier-Thellier VDMs agree well with the VDM measured on 50 Ma-rocks from Western Antarctica (Shcherbakova et al. 2012), and with the lowest values measured on submarine basaltic glass in the same time range (Tauxe 2006). They confirm that the field intensity during the Eocene was much lower than the present-day value and also lower than in the Oligocene and Palaeocene. We did not see any signs of maghemitization in the rocks from Holes U1439C and U1442A, and the magnetizations that they carry are primary, therefore they can be considered as reliable values. The VDMs measured on the FABs from Hole U1440B are higher, and seem to be intermediate between the low values in Eocene and the higher values (closer to the present-day value) that have been measured for Palaeocene. However, our values must be considered with care since they are not of very good quality. Moreover, it should be kept in mind that the palaeosecular variation may not be adequately averaged in our palaeointensity experiments because of the few units sampled.

Using Thellier-Thellier or Coe methods on bulk submarine basalts for obtaining reliable palaeointensities is not always possible. Several factors have been reported lead to erroneous values: the presence of multidomain grain effects and strong viscous remanence can overestimate the palaeointensity result (Carlut \& Kent 2002; Tauxe \& Love 2003). The rocks used in this study are not troubled by these problems, mostly thanks to the ideal grain size of the magnetization carriers. Moreover, the different rock types in Holes U1439C and U1442A give the same palaeointensity values: this implies that there is no grain size or mineralogy effect on the results. 
MSP-DSC
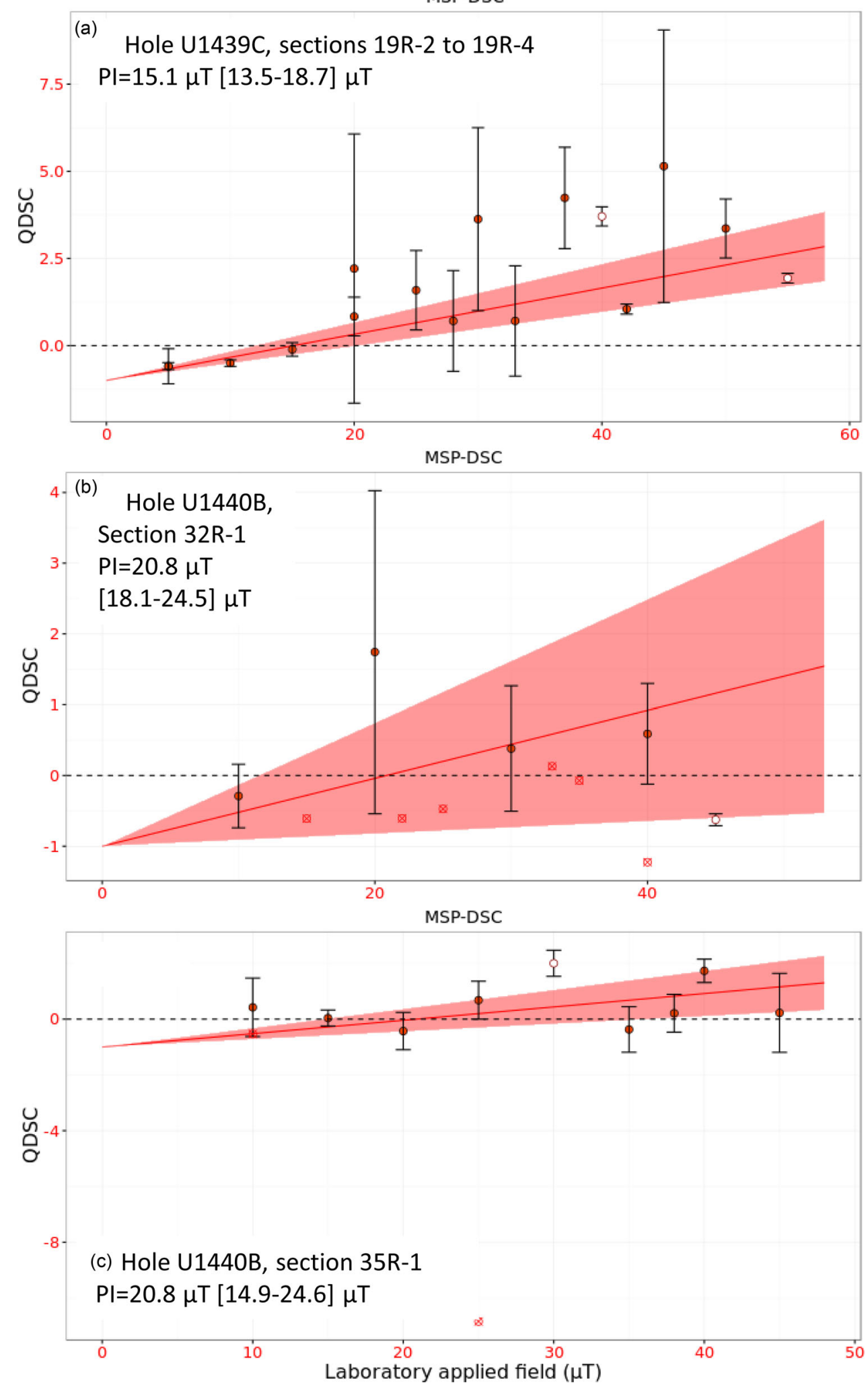

Figure 9. Domain-state corrected multispecimen (MSP-DSC) palaeointensity determinations for (a) samples from Hole U1439C, from sections 19R-2 to 19R-4; (b) samples from Hole U1440B, from section 32R-1, and (c) samples from Hole U1440B, from section 35R-1. Closed (open) symbols represent data used (rejected) in the robust regression of the responses in $Q$ parameters on the predictors of magnetic field $B$. Data and fitting lines are calculated with $\alpha=0.5$. The interval in grey is delimited by 65 per cent confidence intervals on the best fitting lines. 


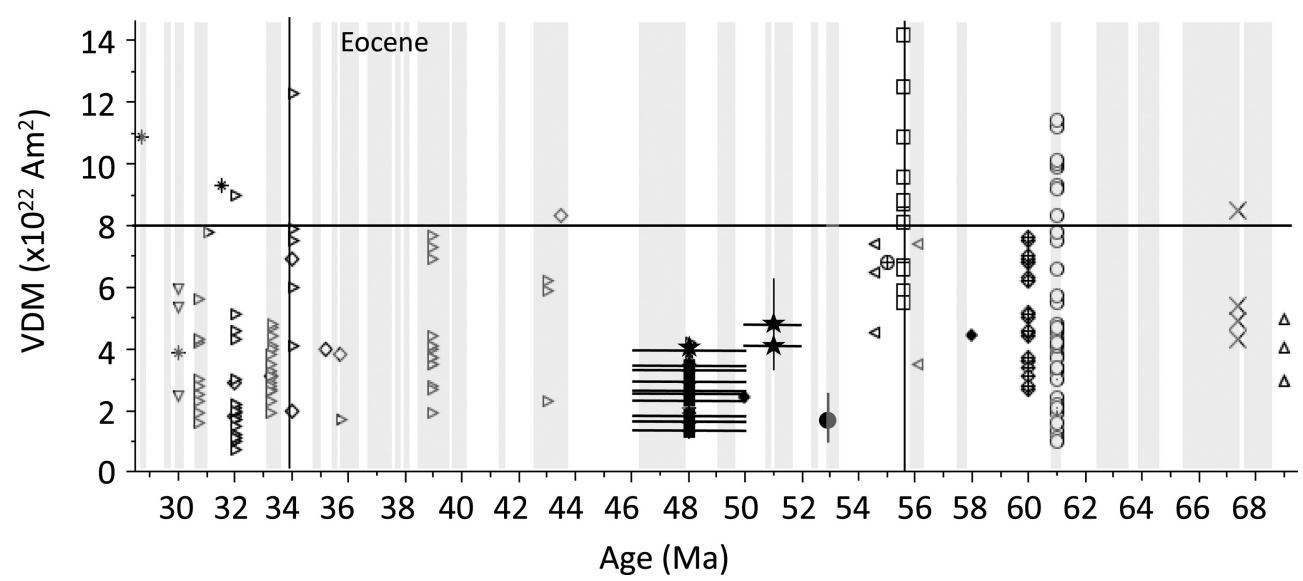

Figure 10. Summary of the VDM data in the 30-70 Ma time range. Available Thellier-Thellier and microwave data from the PINT database (Biggin et al. 2010) are plotted together with data from this study. The present-day VDM is shown as a line at $8 \times 10^{22} \mathrm{Am}^{2}$. Our data are plotted with the full black symbols together with their error bars (squares: Thellier-Thellier results; stars: MSP results). Data represented by—crosses: Goguitchaishvili et al. (2004); circled crosses: Carvallo et al. (2004); filled diamonds: Shcherbakova et al. (2012); empty diamonds: Juárez et al. (1998); triangles pointing rightward: Tauxe (2006); triangles pointing leftward: Riisager et al. (2002); upward triangles: Perrin et al. (1999); downward triangles: Riisager et al. (1999); diamonds and crosses: Riisager et al. (2004); empty circles: Riisager \& Abrahamsen (2000) without transitional flows; stars: Tanaka et al. (2007); empty squares: Tarduno \& Cottrell (2005); black circle: Hill et al. (2002). Data from Juárez et al. (1998) and Tauxe (2006) come from submarine basaltic glass; data from Tarduno \& Cottrell (2005) come from single-crystals; all other are from whole rocks.

Nevertheless, this study supports the conclusion that the intensity of the field during the Eocene was low, while the reversal rate of the field in this period was only 1.55 reversals/Ma, which is low compared with those of Miocene or Jurassic. Even if the ages are not well-constrained yet, the palaeointensity values from Holes U1439C and U1442A come from polarity intervals that are quite long (1-2 Ma). For this period of time, the inverse relationship between reversal rate and geomagnetic field intensity documented by Tarduno et al. (2006) and Tauxe (2006), based on measurements on plagioclase single-crystals and submarine basaltic glass that are younger than Jurassic, does not appear to hold.

\section{CONCLUSIONS}

(1) Thellier-Thellier palaeointensity determinations on 60 submarine samples from andesite and boninite from Holes U1439C and U1442A cored during IODP Expedition 352 on the IzuBonin-Mariana forearc gave 25 high-quality, consistent and reliable palaeointensity values that lead to VDMs that are between a half and a third of the present day VDM.

(2) MSP palaeointensity determinations on one group of 20 samples from Hole U1439C and 51 samples in four groups from FABs drilled in Hole U1440B gave poor quality results. Nevertheless, the palaeointensity value obtained for Hole U1439C is low and consistent with the Thellier-Thellier results, and the values for Hole U1440B, where rocks are 2-4 Ma older than rocks from Hole U1439C, lead to VDM values that are slightly higher than those extracted from the boninites and andesites from Holes U1439C and U1442A.

(3) A good thermal stability, the presence of fine grainedmagnetite as the magnetization carrier, and the absence of important secondary magnetizations explains the Thellier-Thellier success rate, which is unusually high for submarine basalts.

(4) These results provide data for the Eocene period, for which data are scarce, and they confirm prior results that the field intensity was low.

\section{ACKNOWLEDGEMENTS}

This research used samples and data provided by the International Ocean Discovery Program (IODP). The FUReMAG rapid furnace construction was supported by the French National Agency for Research (ANR-12-BS06-0015). Funding for this research was provided by IODP-France. We thank Yohan Guyodo and France Lagroix for helpful discussions and for help using the MPMS. We thank Greig Paterson and an anonymous reviewer for constructive reviews.

\section{REFERENCES}

Biggin, A.J. \& Paterson, G.A., 2014. A new set of qualitative reliability criteria to aid inferences on palaeomagnetic dipole moment variations through geological time, Front. Earth Sci., 2, 24, doi:10.3389/feart.2014.00024.

Biggin, A.J. \& Poidras, T., 2006. First-order symmetry of weak-field partial thermoremanence in multi-domain ferromagnetic grains. 1. Experimental evidence and physical implications, Earth planet. Sci. Lett., 245 (1-2), 438-453.

Biggin, A.J., McCormack, A. \& Roberts, A., 2010. Palaeointensity database updated and upgraded, EOS, Trans. Am. geophys. Un., 91, 15.

Carlut, J. \& Kent, D.V., 2002. Grain-size-dependent paleointensity results from very recent mid-oceanic ridge basalts, J. geophys. Res., 107(B3), doi:10.1029/2001JB000439.

Carvallo, C., 2017. Data report: hysteresis properties of igneous rocks from holes U1439C, U1440B and U1442A, in Proc. IODP, 352, eds Reagan, M.K., Pearce, J.A., Petronotis, K. \& the Expedition 352 Scientists, Integrated Ocean Drilling Program Management International, Inc., Tokyo.

Carvallo, C., Özdemir, Ö \& Dunlop, D.J., 2004. Palaeointensity determinations, palaeodirections and magnetic properties of basalts from the Emperor seamounts, Geophys. J. Int., 156, (1), 29-38. Corrigendum: 158, (3), 898-898.

Carvallo, C., Roberts, A.P., Leonhardt, R., Laj, C., Kissel, C., Perrin, M. \& Camps, P., 2006. Increasing the efficiency of paleointensity analyses by selection of samples using first-order reversal curve diagrams, J. geophys. Res., 111, B12103, doi:10.1029/2005JB004126.

Carvallo, C., Camps, P., Ooga, M., Fanjat, G. \& Sager, W.W., 2013. Palaeointensity determinations and rock magnetic properties on basalts from 
Shatsky Rise: new evidence for a mesozoic dipole low, Geophys. J. Int., 192(3), 986-999.

Coe, R.S., 1967. The determination of paleointensities of the Earth's magnetic field with special emphasize on mechanisms which could cause nonideal behavior in Thellier's method, J. Geomagn. Geoelec., 19(3), 157-179.

Coe, R.S., Grommé, S. \& Mankinen, E.A., 1978. Geomagnetic paleointensities from radiocarbon-dated lava flows on Hawaii and the question of the Pacific nondipole low, J. geophys. Res., 83, 1740-1756.

de Groot, L.V., Dekkers, M.J. \& Mullender, T.A.T., 2012. Exploring the potential of acquisition curves of the anhysteretic remanent magnetization as a tool to detect subtle magnetic alteration induced by heating, Phys. Earth planet. Inter., 194, 71-84.

Dekkers, M.J. \& Böhnel, H.N., 2006. Reliable absolute palaeointensities independent of magnetic domain state, Earth planet. Sci. Lett., 248(1-2), 508-517.

Dunlop, D.J., 2002. Theory and application of the Day plot $\left(M_{\mathrm{rs}} / M_{\mathrm{S}}\right.$ versus $\left.H_{\mathrm{cr}} / H_{\mathrm{c}}\right), 1$. Theoretical curves and tests using titanomagnetite data, $J$. geophys. Res., 107(B3), 2056, doi:10.1029/2001JB000486.

Dunlop, D.J. \& West, G.F., 1969. An experimental evaluation of single domain theories, Rev. Geophys., 7(4), 709-757.

Egli, R., 2013. VARIFORC: An optimized protocol for calculating nonregular first-order reversal curve (FORC) diagrams, Glob. Planet. Change, 110, 302-320.

Fabian, K. \& Leonhardt, R., 2010. Multiple-specimen absolute paleointensity determination: an optimal protocol including pTRM normalization, domain-state correction, and alteration test, Earth planet. Sci. Lett., 207, 84-94.

Fanjat, G., 2012. 'Les fluctuations du champ magnétique terrestre: des variations séculaires récentes aux renversements'. Available at: https:// tel.archives-ouvertes.fr/tel-00719380, last accessed November 2016.

Gattacceca, J., Rochette, P., Lagroix, F., Mathé, P.-E. \& Zanda, B., 2011. Low temperature magnetic transition of chromite in ordinary chondrites, Geophys. Res. Lett., 38, L10203, doi:10.1029/2011GL047173.

Goguitchaichvili, A., Alva-Valdivia, L.M., Rosas-Elguera, J., UrrutiaFucugauchi, J. \& Sol, J., 2004. Absolute geomagnetic paleointensity after the cretaceous normal superchron and just prior to the cretaceous-tertiary transition, J. geophys. Res., 109, doi:10.1029/2003JB002477.

Hall, R., Ali, J.R., Anderson, C.D. \& Baker, S.J., 1995. Origin and motion history of the Philippine Sea Plate, Tectonophysics, 251, 229-250.

Hill, M.J., Gratton, M.N. \& Shaw, J., 2002. Palaeomagnetic investigation of Tertiary lava from Barrington Tops, NSW, Australia, using thermal and microwave techniques, Earth planet. Sci. Lett., 198, 245-256.

Hunt, C., Moskowitz, B. \& Banerjee, S., 1995. Magnetic properties of rocks and minerals, in Rock Physics and Phase Relations: A Handbook of Physical Constants, pp. 189-204, ed. Ahrens, T.J., American Geophysical Union.

Ishikawa, Y., 1962. Magnetic properties of Ilmenite-Hematite system at low temperatures, J. Phys. Soc. Japan, 17(suppl. B-1), 239-243.

Ishizuka, O. et al., 2011. The timescales of subduction initiation and subsequent evolution of an oceanic island arc, Earth planet. Sci. Lett., 306, 229-240.

Juárez, M.T., Tauxe, L., Gee, J.S. \& Pick, T., 1998. The intensity of the Earth's magnetic field over the past 160 million years, Nature, 394, 878881.

Kirschvink, J.L., 1980. The least-squares line and plane and the analysis of palaeomagnetic data, Geophys. J. Int., 62(3), 699-718.

Leonhardt, R., Hufenbecher, F., Heider, F. \& Soffel, H.C., 2000. High absolute paleointensity during a mid Miocene excursion of the Earth's magnetic field, Earth planet. Sci. Lett., 184, 141-154.

Leonhardt, R., Heunemann, C. \& Krása, D., 2004. Analysing absolute palaeointensity determinations: acceptance criteria and the software Thelliertool4.0, Geochem. Geophys. Geosyst., 5(12), doi: 10.1029/2004GC000807.

McFadden, P.L \& Reid, A., 1982. Analysis of paleomagnetic inclination data, Geophys. J. R. astr. Soc., 69, 307-319.

Monster, M.W.L., de Groot, L.V., Biggin, A.J. \& Dekkers, M.J., 2015. The performance of various palaeointensity techniques as a function of rock magnetic behaviour - a case study for La Palma, Phys. Earth planet. Inter., 242, 36-49.

Moskowitz, B.M., Jackson, M. \& Kissel, C., 1998. Low temperature behaviour of titanomagnetites, Earth planet. Sci. Lett., 157, 141-149.

Nagata, T., Arai, Y. \& Momose, K., 1963. Secular variation of the geomagnetic total force during the last 5000 years, J. geophys. Res., 68, $5277-5281$.

Perrin, M., Riisager, J. \& Joseph, M., 1999. Preliminary paleointensity results from dolerite dyke swarm in central Kerala, India, Geol. Soc. India Mem., 44, 261-270.

Pike, R.P., Roberts, A.P. \& Verosub, K.L., 1999. Characterizing interactions in fine magnetic particle systems using first order reversal curves, J. Appl. Phys., 85, 6660-6667.

Prévot, M., Mankinen, E.A., Coe, R.S. \& Grommé, C.S., 1985. The Steens mountain (Oregon) geomagnetic polarity transition. 2. Field intensity variations and discussion of reversal models, J. geophys. Res., 90, $10417-10448$.

Reagan, M.K. et al., 2010. Fore-arc basalts and subduction initiation in the Izu-Bonin-Mariana system, Geochem. Geophys. Geosyst., 11, Q03X12, doi:10.1029/2009GC002871.

Reagan, M.K., McClelland, W.C., Girard, G., Goff, K.R., Peate, D.W., Ohara, Y. \& Stern, R.J., 2013. The geology of the southern Mariana fore-arc crust: implications for the scale of Eocene volcanism in the western Pacific, Earth planet. Sci. Lett., 380, 41-51.

Reagan, M.K., Pearce, J.A., Petronotis, K. \& Expedition 352 Scientists, 2015a. Expedition 352 summary, Proc. IODP, 352, doi:10.14379/iodp.proc.352.101.2015.

Reagan, M.K. et al., 2015b. Site U1439, in Izu-Bonin-Mariana Fore Arc., Proc. IODP, 352, eds Reagan, M.K., Pearce, J.A. \& Petronotis, K., and the Expedition 352 Scientists, doi:10.14379/iodp.proc.352.103.2015.

Reagan, M.K. et al., 2015c. Site U1440, in Izu-Bonin-Mariana Fore Arc., Proc. IODP, 352, eds Reagan, M.K., Pearce, J.A. \& Petronotis, K., and the Expedition 352 Scientists, doi:10.14379/iodp.proc.352.104.2015.

Reagan, M.K. et al., 2015d. Site U1442, in Izu-Bonin-Mariana Fore Arc., Proc. IODP, 352, eds Reagan, M.K., Pearce, J.A. \& Petronotis, K., and the Expedition 352 Scientists, doi:10.14379/iodp.proc.352.106.2015.

Reagan, M.K. et al., 2017. Subduction initiation and ophiolite crust: new insights from IODP drilling, Int. Geol. Rev., 59(11), 1439-1450.

Riisager, J., Perrin, M. \& Rochette, P., 1999. Palaeointensity results from ethiopian basalts: implications for the oligocene geomagnetic field strength, Geophys. J. Int., 138, 590-596.

Riisager, J., Riisager, P., Zhao, X.X., Coe, R.S. \& Padersen, A.K., 2004. Paleointensity during a chron C26r excursion recorded in west Greenland lava flows, J. geophys. Res., 109, doi:10.1029/2003JB002887.

Riisager, P. \& Abrahamsen, N., 2000. Palaeointensity of west Greenland Palaeocene basalts: asymmetric intensity around the C27n-C26r transition, Phys. Earth planet. Inter., 118, 53-64.

Riisager, P., Riisager, J., Abrahamsen, N. \& Waastein, R., 2002. Thellier palaeointensity experiments on Faroes flood basalts: technical aspects and geomagnetic implications, Phys. Earth planet. Inter., 131, 91-100.

Roberts, A.P., Pike, C.R. \& Verosub, K.L., 2000. FORC diagrams: a new tool for characterizing the magnetic properties of natural samples, J. geophys. Res., 105, 28 461-28 475.

Sager, W.W., Clark, R.W. \& Carvallo, C., 2017. Paleomagnetic measurements on Expedition 352 basalt samples, in Proceedings of the Integrated Ocean Drilling Program, vol. 352, in press.

Selkin, P.A. \& Tauxe, L., 2000. Long term variations in palaeointensity, Phil. Trans. R. Soc. A, 358(1768), 1065-1088.

Shcherbakova, V.V., Bakhmutov, V.G., Shcherbakov, V.P., Zhidkov, G.V. \& Shpyra, V.V., 2012. Palaeointensity and palaeomagnetic study of Cretaceous and Palaeocene rocks from Western Antarctica, Geophys. J. Int., 189, 204-228.

Stern, R.J., Fouch, M.J. \& Klemperer, S.L., 2003. An overview of the Izu-Bonin-Mariana subduction factory, in Inside the Subduction Factory, Geophysical Monograph, vol. 138, pp. 175-222, ed. Eiler, J., American Geophysical Union. 
Tanaka, H., Takahashi, N. \& Zheng, Z., 2007. Paleointensities from Tertiary basalts, Inner Mongolia and Hebei Province, northeastern China, Earth planet. Space, 59, 747-754.

Tarduno, J.A. \& Cottrell, R.D., 2005. Dipole strength and variation of the time-averaged reversing and nonreversing geodynamo based on Thellier analyses of single plagioclase crystals, J. geophys. Res., 110, doi:10.1029/2005JB003970.

Tarduno, J.A., Cottrell, R.D. \& Smirnov, A.V., 2006. The paleomagnetism of single silicate crystals: recording geomagnetic field strength during mixed polarity intervals, superchrons, and inner core growth, Rev. Geophys., 44, RG1002, doi:10.1029/2005RG000189.
Tauxe, L., 2006. Long-term trends in paleointensity: the contribution of DSDP/ODP submarine basaltic glass collections, Phys. Earth planet. Inter., 156, 223-241.

Tauxe, L. \& Love, J.J., 2003. Paleointensity in Hawaiian scientific drilling project hole (HSDP2): results from submarine basaltic glass, Geochem. Geophys. Geosyst., 4(2), 8702, doi:10.1029/2001GC000276.

Thellier, E. \& Thellier, O., 1959. Sur l'intensité du champ terrestre dans le passé historique et géologique, Ann. Geophys., 15, 295-378.

Yu, Y. \& Tauxe, L., 2005. Testing the IZZI protocol of geomagnetic field intensity determination, Geochem. Geophys. Geosyst., 6, Q05H17, doi:10.1029/2004GC000840. 